\title{
Influence of glacial ice sheets on the Atlantic meridional overturning circulation through surface wind change
}

\author{
Sam Sherriff-Tadano $^{1}$ (D) Ayako Abe-Ouchi ${ }^{1} \cdot$ Masakazu Yoshimori $^{2} \cdot$ Akira Oka $^{1}$. \\ Wing-Le Chan ${ }^{1}$
}

Received: 16 January 2017 / Accepted: 22 June 2017 / Published online: 31 July 2017

(c) The Author(s) 2017. This article is an open access publication

\begin{abstract}
Coupled modeling studies have recently shown that the existence of the glacial ice sheets intensifies the Atlantic meridional overturning circulation (AMOC). However, most models show a strong AMOC in their simulations of the Last Glacial Maximum (LGM), which is biased compared to reconstructions that indicate both a weaker and stronger AMOC during the LGM. Therefore, a detailed investigation of the mechanism behind this intensification of the AMOC is important for a better understanding of the glacial climate and the LGM AMOC. Here, various numerical simulations are conducted to focus on the effect of wind changes due to glacial ice sheets on the AMOC and the crucial region where the wind modifies the AMOC. First, from atmospheric general circulation model experiments, the effect of glacial ice sheets on the surface wind is evaluated. Second, from ocean general circulation model experiments, the influence of the wind stress change on the AMOC is evaluated by applying wind stress anomalies regionally or at different magnitudes as a boundary condition. These experiments demonstrate that glacial ice sheets intensify the AMOC through an increase in the wind stress at the North Atlantic mid-latitudes, which is induced by the North American ice sheet. This intensification of
\end{abstract}

Electronic supplementary material The online version of this article (doi:10.1007/s00382-017-3780-0) contains supplementary material, which is available to authorized users.

Sam Sherriff-Tadano

tadano@aori.u-tokyo.ac.jp

1 Atmosphere and Ocean Research Institute, University of Tokyo, 5-1-5 Kashiwanoha, Kashiwa 277-8568, Japan

2 Faculty of Environmental Earth Science, Global Institute for Collaborative Research and Education, and Arctic Research Center, Hokkaido University, Sapporo, Japan the AMOC is caused by the increased oceanic horizontal and vertical transport of salt, while the change in sea ice transport has an opposite, though minor, effect. Experiments further show that the Eurasian ice sheet intensifies the AMOC by directly affecting the deep-water formation in the Norwegian Sea.

Keywords Glacial climate $\cdot$ AMOC $\cdot$ Ice sheet $\cdot$ Surface wind

\section{Introduction}

Ice sheets play a crucial role in the climate system. The existence of the ice sheets not only affects the global sea level, but also the surface air temperature, atmospheric circulation and ocean circulation. Over the Quaternary, the configuration of the ice sheets has changed dramatically in response to insolation changes and associated nonlinear feedbacks (e.g. Lisiecki and Raymo 2005; Abe-Ouchi et al. 2013). During Quaternary glacial times, the North American (Laurentide/Cordilleran, e.g. Stokes et al. 2012) and Eurasian ice sheets grew individually across the continents (hereafter referred to as glacial ice sheets). The glacial ice sheets exerted a substantial impact on the atmospheric circulation and glacial climate (e.g. Manabe and Broccoli 1985; Broccoli and Manabe 1987; Roe and Lindzen 2001a, b; Chiang et al. 2003; Chiang and Bitz 2005; Abe-Ouchi et al. 2007; Langen and Vinther 2009; Yanase and AbeOuchi 2010; Singarayer and Valdes 2010; Chavaillaz et al. 2013). Especially in the North Atlantic, the Icelandic Low and Azores High intensified and the wind fields at high latitudes were also modified due to the topography of the North American ice sheet as well as the albedo and cooling over the ice sheet (Cook and Held 1988; Ringler and Cook 
1997, 1999; Pausata et al. 2011; Liakka et al. 2012; Liakka 2012).

Recently, in the context of the Paleoclimate Modeling Intercomparison Project (PMIP, Braconnot et al. 2007, 2012), simulations of the last glacial maximum (LGM) have been conducted with atmosphere-ocean coupled general circulation models (AOGCMs). These simulations made it possible to explore the impact of the glacial boundary conditions on the Atlantic Meridional Overturning Circulation (AMOC). While reconstructions suggested both a weaker and stronger AMOC during the LGM (McManus et al. 2004; Lynch-Stieglitz et al. 2007; Gherardi et al. 2009; Lippold et al. 2012; Böhm et al. 2015), most of the AOGCMs (except CCSM3 and HadCM3 in PMIP2) in the PMIP showed a strong AMOC in their LGM simulations (Weber et al. 2007; Otto-Bliesner et al. 2007; Muglia and Schmittner 2015). Moreover, recent sensitivity studies using AOGCMs showed that the existence of the glacial ice sheets intensified the AMOC (Eisenman et al. 2009; Smith and Gregory 2012; Brady et al. 2013; Zhang et al. 2014; Zhu et al. 2014; Gong et al. 2015; Brown and Galbraith 2016; Kawamura et al. 2017). Therefore, in order to improve our understanding of the glacial climate and the LGM AMOC, it is essential to understand how glacial ice sheets affected the AMOC.

To investigate why the AMOC during the LGM was stronger than the Preindustrial as simulated in the Model for Interdisciplinary Research on Climate 4m (MIROC4m; Hasumi and Emori 2004) AOGCM in the PMIP2 (Weber et al. 2007), Oka et al. (2012, hereafter OHA12) conducted sensitivity experiments with an ocean general circulation model (OGCM) decoupled from MIROC4m. The decoupling of the OGCM from the AOGCM helped identify the important processes controlling the AMOC, which was more complex in the AOGCMs due to the coupling process. By applying the surface condition computed in the MIROC4m Preindustrial and LGM simulations as a boundary condition to the OGCM, they found that the LGM wind stress was crucial for the intensification of the AMOC. They suggested that the changes in salt transport were important, which affected the sea surface density and deepwater formation (e.g. Oka et al. 2001; Born et al. 2010). While the study of OHA12 was based on the glacial wind simulated by MIROC4m, the role of the glacial wind was further confirmed by Muglia and Schmittner (2015), who also showed that the glacial wind over the Northern Hemisphere (Atlantic) intensified the AMOC in all of the PMIP3 and PMIP2 models.

Changes in the salt transport could be induced by winddriven ocean processes, wind-driven sea ice processes or both. For example, wind anomalies at low, mid and high latitudes could modify the gyre circulation as well as Ekman upwelling, downwelling and convective mixing.
This has a substantial impact on the horizontal and vertical salt transport, which affects the AMOC (Oka et al. 2001, Timmerman and; Goosse 2004; Montoya and Levermann 2008; Saenko 2009a, b; Montoya et al. 2011; Zhong et al. 2011). In addition, wind anomalies at mid-high latitudes could modify the wind-driven sea ice transport (Born et al. 2010; Zhong et al. 2011; Zhu et al. 2014; Zhang et al. 2014). This modifies the sea ice coverage and regions of sea ice melt, which affects the AMOC.

To summarize, previous studies have shown that the glacial wind over the North Atlantic intensified the AMOC in the PMIP LGM simulations. The glacial ice sheets were considered to play an important role and changes in the salt transport were shown as key to the enhancement of the AMOC. However, several points remained elusive in these studies. First, since both OHA12 and Muglia and Schmittner (2015) used only the Preindustrial and LGM wind and did not distinguish between the impact of glacial ice sheets and that of other factors $\left(\mathrm{CO}_{2}\right.$, sea surface conditions), the impact of glacial ice sheet wind on the AMOC was somewhat vague. In addition, the role of individual ice sheets (the North American and Eurasian ice sheets) remained unclear. This is very important, especially when we want to apply our knowledge to other glacial periods as the North American and Eurasian ice sheets did not wax and wane in concert during the glacial periods (Abe-Ouchi et al. 2013; Hughes et al. 2016). Second, it still remained unclear as to which region of the wind field in the North Atlantic was important for the intensification of the AMOC as the wind field was largely modified over the entire North Atlantic. This is also related to the uncertainty in the important mechanism, as changes in the wind in the North Atlantic could modify the salt transport and hence the AMOC by affecting the wind-driven oceanic circulation or by affecting the wind-driven sea ice transport.

In this study, we first clarify the important factors for the intensification of the AMOC through modification of the surface wind (e.g. the North American ice sheet, the Eurasian ice sheet or other effects). Then we investigate in which regions the wind anomalies are important, and the mechanism by which they modify the AMOC. For this purpose, we conduct a series of sensitivity experiments using an atmospheric general circulation model (AGCM) and an OGCM decoupled from an AOGCM. In this method, the atmosphere and the ocean do not interact with one another so that we can apply surface conditions as boundary conditions to the OGCM, which enables us to clearly evaluate the effect of the wind change due to the glacial ice sheets on the ocean circulation and on the AMOC. Moreover, by taking advantage of the decoupled nature, we can conduct several sensitivity experiments and decompose the glacial ice sheet effect into the North American effect and the Eurasian effect. In addition, we can investigate the regions 
in which the wind change is crucial and the mechanism by which it influences the AMOC. In this way we can systematically investigate the wind change effect due to the glacial ice sheets on the AMOC.

The present paper is organized as follows. In Sect. 2, we describe the model and the experimental setup. In Sect. 3, we investigate the effect of glacial ice sheets on the atmospheric circulation by running AGCM experiments. In Sect. 4, we investigate the effect of the glacial ice sheets on the AMOC through surface wind change and the regions of crucial importance. In Sect. 5, we discuss our results and lastly, we present our conclusions in Sect. 6.

\section{Methodology}

\subsection{Model and experimental setup}

We use an atmospheric component and an oceanic component of the coupled model MIROC4m, which participated in the PMIP2 (Braconnot et al. 2007). The performance of MIROC $4 \mathrm{~m}$ has been assessed extensively for both modern climate (e.g. Nozawa et al. 2005; O'ishi and Abe-Ouchi 2009; Ohgaito and Abe-Ouchi 2009; Yanase and AbeOuchi 2010; Watanabe et al. 2010) and paleoclimate, the latter of which is compared to other models and reconstructions in the context of PMIP (e.g. Kageyama et al. 2006; Masson-Delmotte et al. 2006; Yanase and Abe-Ouchi 2007; Murakami et al. 2008; Rojas et al. 2009; Otto-Bliesner et al. 2009; Lü et al. 2010). In particular, it is known that MIROC4m simulates a stronger AMOC in its LGM simulation compared to the Preindustrial climate simulation (e.g. Weber et al. 2007; Otto-Bliesner et al. 2007; note that the model integration has been extended to more than 6000 years after these studies, though the result does not change). Even though we use a model that simulates a stronger AMOC in the LGM, our main goal is to understand how glacial ice sheets affect the AMOC by modifying the surface wind field and thus results of MIROC4m are utilized for this purpose.

The AGCM that we use is identical to the uncoupled atmospheric component of MIROC4m (Numaguchi et al. 1997). It is coupled to a land surface model and has a horizontal resolution of T42, which corresponds to an approximate grid resolution of $2.8^{\circ}$, and 20 layers in the vertical. Unlike the coupled model, the sea surface temperature and sea ice are fixed as boundary conditions. The OGCM used in this study is also identical to the uncoupled oceanic component of MIROC4m (Hasumi 2006). It is coupled to a sea ice model, and has a resolution of $\sim 1.4^{\circ}$ in longitude and $0.56^{\circ}-1.4^{\circ}$ in latitude (latitudinal resolution is finer near the equator) and 43 unevenly spaced layers in the vertical. Unlike the coupled model, atmospheric conditions are fixed as boundary conditions (further information can be found below). See Hasumi and Emori (2004) and Chan et al. (2011) for further information on the AGCM and the OGCM of MIROC4m. The AGCM reproduces the surface westerlies over the North Atlantic reasonably well, while it underestimates the southwest-northeast orientation and the strength (Fig. 1). The OGCM reproduces the Preindustrial AMOC and the North Atlantic Deep Water (NADW) formation in the Greenland-Iceland-Norwegian Sea reasonably well (Oka et al. 2008, OHA12).

To run the AGCM, several boundary conditions are required: ice sheet configuration, greenhouse gases, orbital parameters, sea surface temperature and sea ice. We apply either Preindustrial or LGM boundary conditions, the latter of which follows the protocol of the LGM simulation in PMIP2 (Braconnot et al. 2007). This protocol specifies glacial ice sheets (ICE-5G, Peltier 2004), greenhouse gas concentration $\left(\mathrm{CO}_{2}=185 \mathrm{ppm}, \mathrm{CH}_{4}=350 \mathrm{ppb}\right.$ and $\mathrm{NO}_{2}=200 \mathrm{ppb}$; Fluckiger et al. 1999; Dallenbach et al. 2000; Monnin et al. 2001) and orbital parameters. Sea surface temperature and sea ice are taken from the climatology of the MIROC4m Preindustrial or LGM simulations. See Tables 1 and 2 for a detailed design of the experiments. We use the ICE-5G LGM ice sheets in order to be consistent with OHA12. However, some studies have showed that differences between the ice sheet reconstructions of the PMIP3 and ICE-5G have a significant impact on the climate over the North Atlantic (e.g. Abe-Ouchi et al. 2015). The impact of differences in the ice sheet reconstructions on the surface wind will be presented in the discussion. Integration time is 32 years and we use the last 23 years for analysis and for OGCM boundary conditions.

Three types of surface fluxes, heat, momentum and freshwater (E-P-Runoff), are required to run the OGCM. The heat flux is diagnosed from the surface temperature, humidity, short wave radiation and long wave radiation, all of which are taken from the coupled model Preindustrial and LGM simulations as in OHA12. The freshwater flux (E-P-Runoff) is calculated using the evaporation, precipitation and runoff and these are taken directly from the coupled model. Note that the freshwater flux (E-P-Runoff) used here does not include the freshwater flux form the sea ice. This is calculated explicitly in the OGCM. For the momentum flux, surface wind stresses from AGCM experiments are applied. The model is integrated for more than 1000 years from modern climatology of the observed temperature and salinity (Steele et al. 2001). We analyze the last 100 years after verifying that the strength of the AMOC (Supplementary Fig. 1) and deep ocean temperature (below $2000 \mathrm{~m}$ ) has reached a quasi-equilibrium state (the decreasing trend of the deep ocean temperature is less than $0.005^{\circ} \mathrm{C}$ in the last 200 years for all the experiments). In order to focus on the impact of the wind forcing on the 
Fig. 1 Validation of surface wind stress from AGCM. Top figures show annual climatology of surface wind stress $\left(\mathrm{N} / \mathrm{m}^{2}\right.$; averaged over 1981-2010) from ERA-interim (Dee et al. 2011; a) and the AGCM preindustrial climate simulation (A-PI, b). In the bottom figures $(\mathbf{c}, \mathbf{d})$ changes in wind stress (arrow, $\mathrm{N} / \mathrm{m}^{2}$ ) and wind stress curl (color, $10^{-8} \mathrm{~N} / \mathrm{m}^{3}$ ) in the North Atlantic between LGM and Preindustrial in the AOGCM and AGCM are shown
Table 1 Experiments conducted with the AGCM (a) ERA-interim PI

(b) AGCM PI

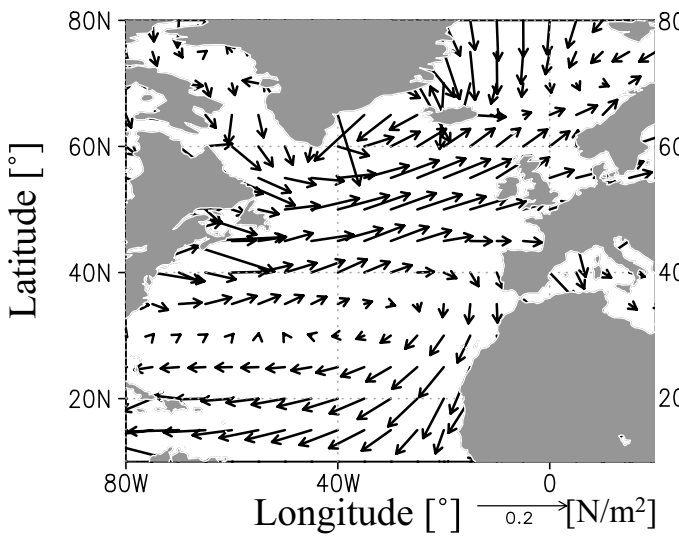

(c) AOGCM LGM-PI
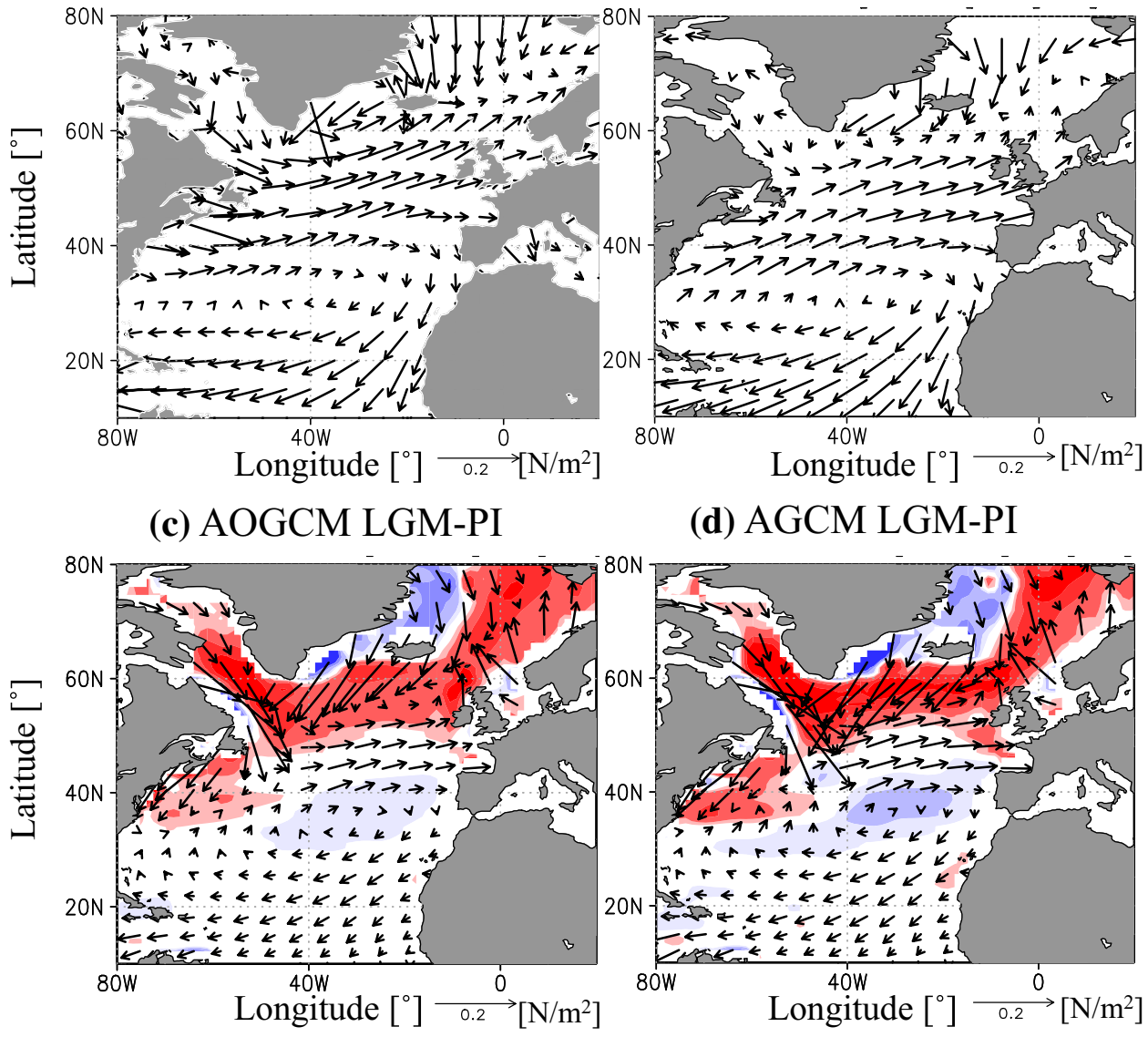

(d) AGCM LGM-PI

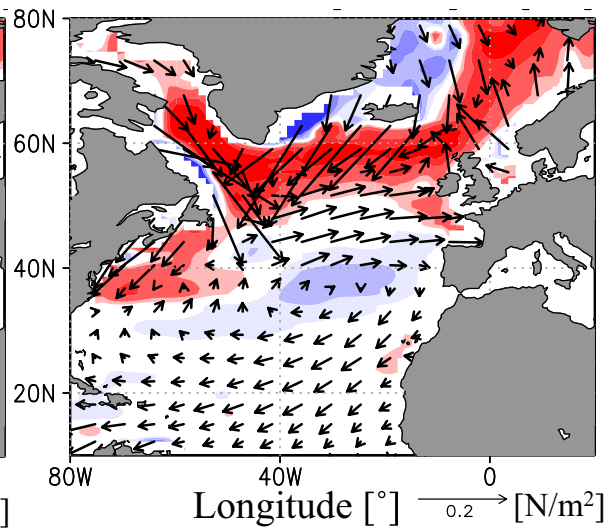

Wind stress curl $\left[10^{-8} \mathrm{~N} / \mathrm{m}^{3}\right]$

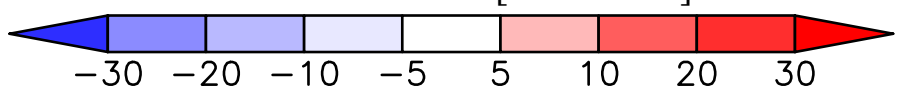

\begin{tabular}{lllll}
\hline Exp name & SST and sea ice & Ice sheet albedo & Ice sheet topography & GHG and insolation \\
\hline A-PI & MIROC4m Preindustrial & Preindustrial & Preindustrial & MIROC4m Preindustrial \\
A-NOICE & MIROC4m LGM & Preindustrial & Preindustrial & PMIP2 LGM \\
A-FULLICE & MIROC4m LGM & ICE5G LGM & ICE5G LGM & PMIP2 LGM \\
A-FLATICE & MIROC4m LGM & ICE5G LGM & Preindustrial & PMIP2 LGM \\
A-NAFULL & MIROC4m LGM & North American & North American & PMIP2 LGM \\
& & only & only & \\
A-EUFULL & MIROC4m LGM & Eurasian only & Eurasian only & PMIP2 LGM \\
\hline
\end{tabular}

For LGM greenhouse gases (GHG) we set $\mathrm{CO}_{2}$ levels to $185 \mathrm{ppm}, \mathrm{CH}_{4}$ to $350 \mathrm{ppb}$ and $\mathrm{NO}_{2}$ to $200 \mathrm{ppb}$ (Fluckiger et al. 1999; Dallenbach et al. 2000; Monnin et al. 2001). For the glacial ice sheet, we used the LGM configuration of ICE-5G (Peltier 2004). The sea surface temperature (SST) and sea ice distribution required to run the AGCM is taken from the climatology of the MIROC4m LGM experiment. For North America (NA) and Eurasia (EU), we only apply the North American and Eurasian glacial ice sheets, respectively ocean circulation, we fix the land-sea mask to modern in all the OGCM experiments following OHA12 (although changes in bathymetry have a large impact on the AMOC
(Hu et al. 2015), its evaluation is not our main purpose). Note that the importance of the wind forcing does not depend on the land-sea mask since OHA12 and Muglia and 
Table 2 Relationship between the effect of the individual boundary condition and sensitivity experiments

\begin{tabular}{ll}
\hline Boundary condition & Difference between two experiments \\
\hline Glacial ice sheets & A-FULLICE minus A-NOICE \\
Topography & A-FULLICE minus A-FLATICE \\
Albedo & A-FLATICE minus A-NOICE \\
North American & A-NAFULL minus A-NOICE \\
Eurasian & A-EUFULL minus A-NOICE \\
Residual effect & A-NOICE minus A-PI \\
\hline
\end{tabular}

We define the albedo effect as A-FLATICE-A-NOICE, the topography effect as A-FULLICE-A-FLATICE, the North American ice sheet effect as A-NAFULL-A-NOICE and the Eurasian ice sheet effect as A-EUFULL-A-NOICE. Many previous studies decompose the albedo and topography effect in the same manner (e.g.: AbeOuchi et al. 2007; Kageyama and Valdes 2000; Ogura and Abe-Ouchi 2001)

Schmittner (2015) showed that changes between the LGM and Preindustrial wind field enhance the AMOC under modern and glacial land-sea masks, respectively. However, since we use the modern land-sea mask for OGCM experiments, this will cause a mismatch between the landsea masks of the AGCM and OGCM (e.g. in the AGCM, the Barents Sea is treated as ice sheet while it is treated as ocean in the OGCM). Thus, when we directly apply wind stress anomalies computed in the AGCM (e.g. differences between LGM and Preindustrial simulations) to the OGCM, unrealistic wind anomalies will appear in these regions. To avoid this unrealistic wind forcing, we do not apply wind stress anomalies over the regions where there is a mismatch of land-sea mask between AGCM and OGCM. However, note that our main results do not depend on whether we apply the unrealistic wind or not. In fact, when we conduct an additional experiment to test whether this unrealistic wind forcing itself has an impact on the AMOC, results show that the impact is very small. This supports our claim that the results presented in this study are not affected by the unrealistic wind forcing.

\subsection{Design of experiments}

Using the AGCM, we first conduct three experiments; A-PI, A-NOICE and A-FULLICE. A-PI is a Preindustrial climate simulation; in A-NOICE we lower the greenhouse gas concentrations and impose LGM orbital forcing. Importantly, we do not change either the surface albedo or topography; and in A-FULLICE (LGM simulation), we further impose LGM surface albedo and topography (Table 1). From these experiments, we define the glacial ice sheet effect as the difference between A-FULLICE and A-NOICE. The residual effect (changes in sea ice, sea surface temperature, greenhouse gases, and insolation) is defined as the difference between A-NOICE and A-PI. As a next step, we decompose the effect of the glacial ice sheets into albedo, topography, North American and Eurasian ice sheets by conducting three sensitivity experiments (A-FLATICE, A-NAFULL, A-EUFULL in Tables 1, 2). In A-FLATICE, we impose the albedo of the glacial ice sheet, but do not change the topography. In A-NAFULL, we impose the albedo and topography of the ice sheet over North America. In A-EUFULL, we impose the albedo and topography of the ice sheet over Europe and Asia. Using these experiments, we define the albedo effect as the difference between A-FLATICE and A-NOICE, the topography effect as the difference between A-FULLICE and A-FLATICE, the North American ice sheet effect as the difference between A-NAFULL and A-NOICE and the Eurasian ice sheet effect as the difference between A-EUFULL and A-NOICE (Tables 1, 2).

For the OGCM, we first conduct two experiments (O-PI and O-LGM); O-PI is a Preindustrial climate simulation, in which we apply the wind field from A-PI and the thermal and freshwater (E-P-Runoff) conditions from the Preindustrial AOGCM simulation; O-LGM is a LGM simulation in which we apply the wind field from A-FULLICE and the thermal and freshwater (E-P-Runoff) conditions from the LGM AOGCM simulation (Tables 3,4). As a next step, in order to explore the effect of glacial ice sheet wind on the glacial AMOC, we apply the wind stresses from the AGCM sensitivity experiments to the OGCM under glacial thermal condition. In O-HEAT we apply the wind stress from A-PI, in O-NOICE we apply wind stress from A-NOICE, in O-FULLICE we apply wind stress from A-FULLICE, in O-NAFULL we apply wind stress from A-NAFULL and in O-EUFULL we apply wind stress from A-EUFULL. From these experiments, we define the glacial ice sheet wind effect as the difference between O-FULLICE and O-NOICE, the residual wind effect as the difference between O-NOICE and O-HEAT, the North American ice sheet wind effect as the difference between O-NAFULL and O-NOICE and the Eurasian ice sheet wind effect as the difference between O-EUFULL and O-NOICE (Tables 3, 4). In these experiments, we apply Preindustrial freshwater fluxes (E-P-Runoff) in order to carry out this investigation in a simple manner. The fact that the changes in the freshwater flux (E-P-Runoff) has only a small impact on the AMOC (OHA12 and Sect. 2.3) supports the rationale for investigating the impact of the glacial ice sheet wind on the AMOC under Preindustrial freshwater flux (E-P-Runoff).

To clarify the important regions where the surface wind anomaly forced by the glacial ice sheet (difference of A-FULLICE and A-NOICE) intensifies the glacial AMOC in the North Atlantic, which was unclear in Muglia and Schmittner (2015), we subdivide the North Atlantic into three latitudinal bands, $0^{\circ}-30^{\circ} \mathrm{N}, 30^{\circ} \mathrm{N}-65^{\circ} \mathrm{N}$ and 
Table 3 Experiments conducted with the OGCM

\begin{tabular}{lllll}
\hline Exp name & Wind stress & Thermal condition & Freshwater flux & AMOC max \\
\hline O-PI & A-PI & MIROC4m Preindustrial & MIROC4m Preindustrial & $16.3[18 \pm 5]$ \\
O-HEAT & A-PI & MIROC4m LGM & MIROC4m Preindustrial & 4.7 \\
O-NOICE & A-NOICE & MIROC4m LGM & MIROC4m Preindustrial & 8.4 \\
O-NAFULL & A-NAFULL & MIROC4m LGM & MIROC4m Preindustrial & 22.9 \\
O-EUFULL & A-EUFULL & MIROC4m LGM & MIROC4m Preindustrial & 21.5 \\
O-FULLICE & A-FULLICE & MIROC4m LGM & MIROC4m Preindustrial & 25.4 \\
O-LGM & A-FULLICE & MIROC4m LGM & MIROC4m LGM & 26.2 \\
\hline
\end{tabular}

Wind stress from the AGCM is used. For the thermal and freshwater (E-P-Runoff) conditions, we use either the glacial condition from the MIROC LGM simulation or the Preindustrial condition from the MIROC Preindustrial simulation. Value inside brackets for O-PI refers to the strength of the modern AMOC from Talley et al. (2003)
Table 4 Relationship between the boundary condition effect and sensitivity experiments

\begin{tabular}{ll}
\hline Boundary condition & Difference between two experiments \\
\hline Glacial ice sheets & O-FULLICE minus O-NOICE \\
North American ice sheet & O-NAFULL minus O-NOICE \\
Eurasian ice sheet & O-EUFULL minus O-NOICE \\
Residual effect & O-NOICE minus O-HEAT \\
\hline
\end{tabular}

$65^{\circ} \mathrm{N}-90^{\circ} \mathrm{N}$, and apply the wind stress anomaly to each of these regions separately in the OGCM. We apply the wind anomaly over $0^{\circ}-30^{\circ} \mathrm{N}$ in O-LOW, we apply the wind anomaly over $30^{\circ} \mathrm{N}-65^{\circ} \mathrm{N}$ in O-MIDDLE and we apply the wind anomaly over $65^{\circ} \mathrm{N}-90^{\circ} \mathrm{N}$ in O-HIGH. We have set the boundary at $65^{\circ} \mathrm{N}$ because it is the lowest latitude where sea ice exists throughout the year in O-NOICE.

\subsection{Reproducibility of the results of AOGCM and OHA12 by decoupled simulations}

Here, we assess whether our decoupled simulations can reproduce the results of MIROC4m and OHA12, because the present study is based on these two sets of results. Figure 1 shows the changes between the LGM and Preindustrial surface wind stresses over the North Atlantic for both the AOGCM and the AGCM. The AGCM reproduces the changes in the AOGCM surface wind field reasonably well, while it overestimates the strengthening of the westerly wind stress at North Atlantic mid-latitudes.

Figure 2 compares the AMOC and the NADW formation regions of the AOGCM and our decoupled OGCM. Decoupled OGCM simulations (O-PI and O-LGM) reproduce both the changes in the strength and the spatial structure of the AOGCM AMOC reasonably well in that the AMOC is stronger and deeper in the LGM simulation compared to the Preindustrial simulation. The AMOC in O-PI is slightly weaker than that in the AOGCM simulations whereas the AMOC in O-LGM is slightly stronger than that in the coupled experiment (Fig. 2). Note that in $\mathrm{O}-\mathrm{LGM}$, the meridional streamfunction around $60^{\circ} \mathrm{N}$ is strong compared to that in the AOGCM LGM simulation. This is possibly related to the slight difference in the region of NADW formation, which lies slightly farther north in O-LGM compared to that of the AOGCM LGM simulation (Fig. 2d, h). However, since O-LGM at least reproduces the maximum strength of the AMOC and also the deepening of the NADW cell compared to O-PI, OGCM simulations successfully reproduce the overall structure of the AMOC in AOGCM.

The wind from the AGCM also reproduces the results of OHA12 in that the Preindustrial wind (A-PI) produces a weak AMOC (O-HEAT) and the LGM wind (A-FULLICE) produces a strong AMOC (O-FULLICE) under glacial thermal and Preindustrial freshwater (E-P-Runoff) conditions. Note that OHA12 used the winds from MIROC4m. They suggested that the weakening of the AMOC in O-HEAT is caused by the southward expansion of sea ice in the North Atlantic due to the cooling, which insulates heat exchange between the atmosphere and ocean and weakens the deepwater formation. The same results are obtained under glacial thermal and freshwater conditions (not shown). This is also consistent with OHA12, who showed that changes in the freshwater flux (E-P-Runoff) between the Preindustrial and glacial climates have a relatively small impact on the strength of the AMOC compared to changes in the thermal and momentum conditions.

\section{Results from the AGCM}

In this section, we first decompose the difference between the LGM and Preindustrial winds computed in MIROC4m into glacial ice sheet effect and residual effects. We then investigate the general features of the atmospheric circulation change induced by the glacial ice sheets and further decompose the glacial ice sheet effect. 
(a) MIROC4m Preindustrial

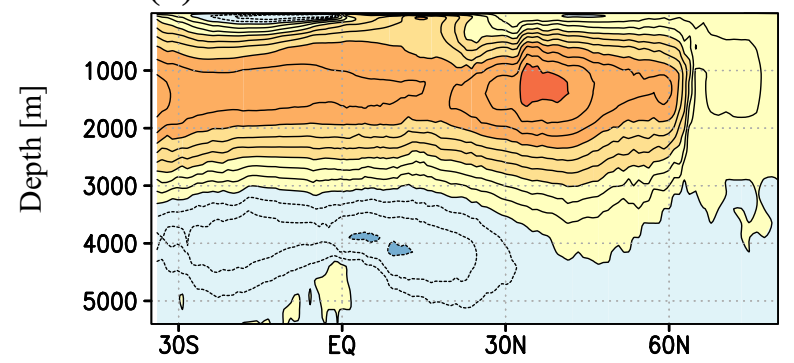

(b) MIROC4m LGM (PMIP2)

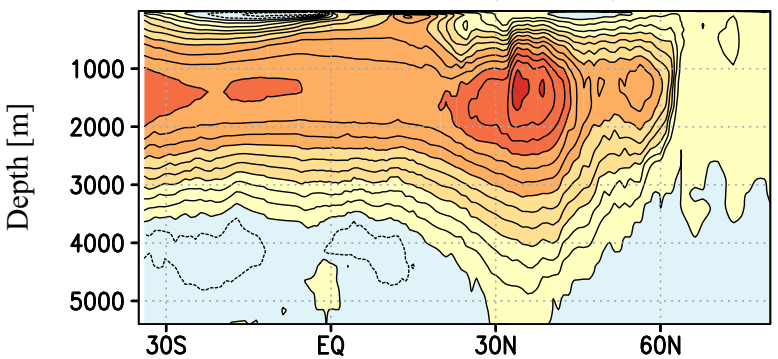

(c) MIROC4m LGM - Preindustrial

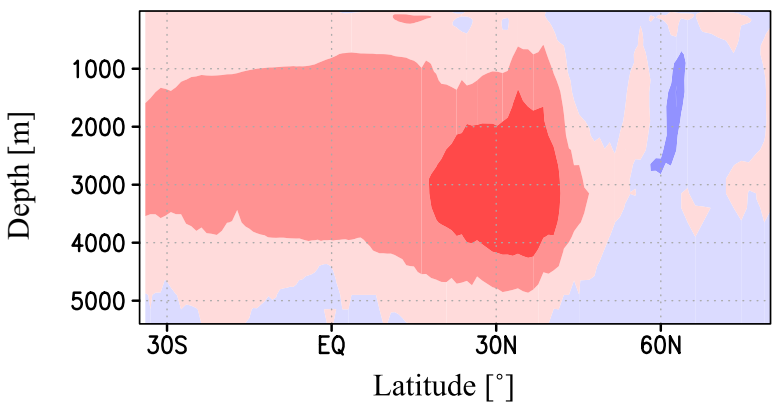

(d) MIROC4m LGM Mixed layer depth

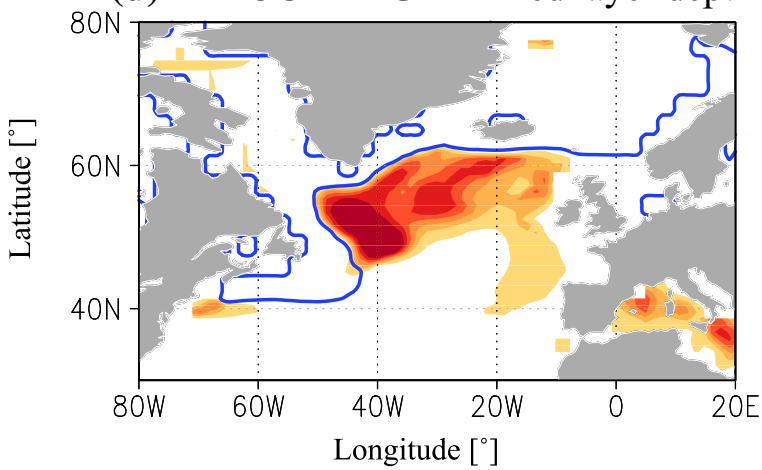

Fig. 2 Comparison of the results from MIROC4m (left) and OGCM (right). In the OGCM simulations, heat and freshwater fluxes are calculated using the variables taken from the corresponding MIROC4m simulations, while the wind stress is taken from corresponding AGCM simulations. The meridional streamfunction in the North

Figure 3 shows the annual mean surface wind field from the AGCM experiments A-PI, A-NOICE and A-FULLICE. By examining the anomaly field, it is obvious that the difference between A-FULLICE and A-PI is dominated by the (e) OGCM Preindustrial (O-P!)

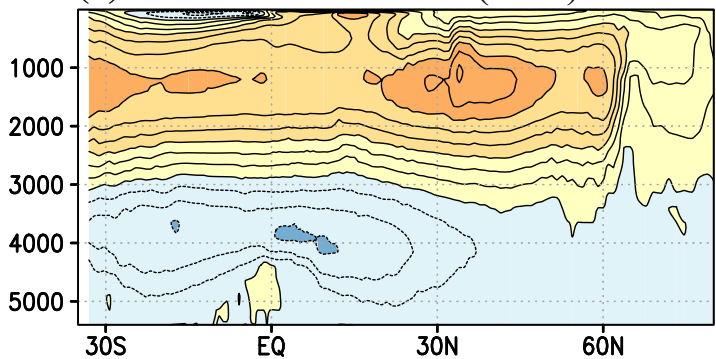

(f) OGCM LGM (O-LGM)

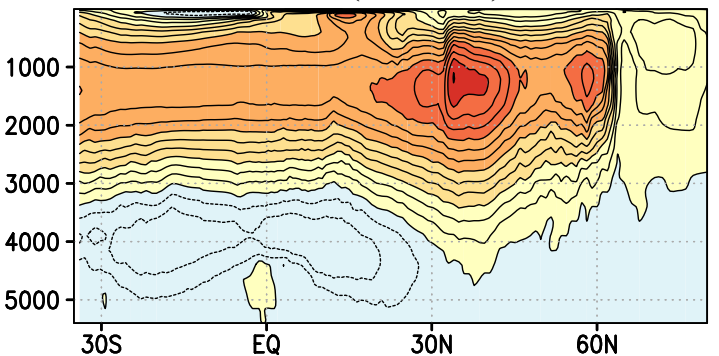

(g) OGCM LGM - Preindustrial

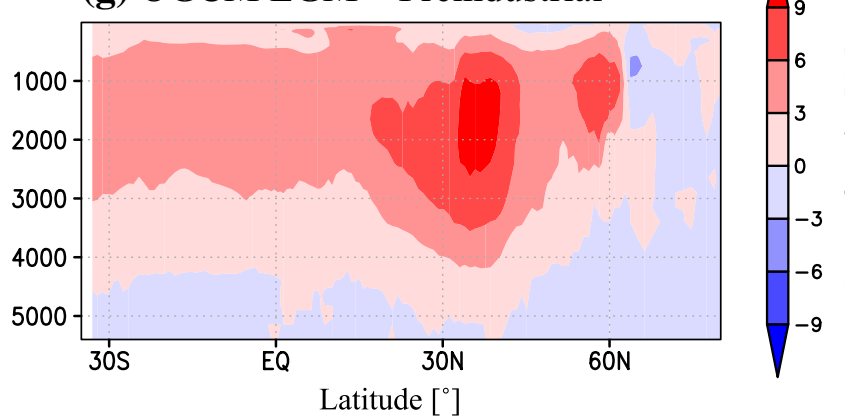

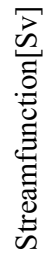

(h) OGCM LGM Mixed layer depth

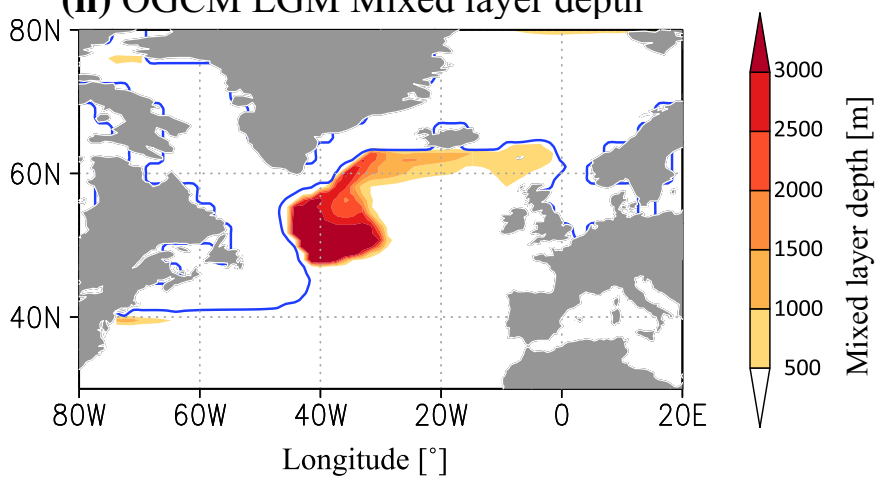

Atlantic from the Preindustrial simulation (a, e), the LGM simulation $(\mathbf{b}, \mathbf{f})$ and the difference between the LGM and Preindustrial simulations $(\mathbf{c}, \mathbf{g})$ are shown. In $\mathbf{d}, \mathbf{h}$ the February mixed layer depth from the LGM simulations are shown, when the deep-water formation becomes vigorous

glacial ice sheet effect, which is deduced from the difference between A-FULLICE and A-NOICE. Changes in sea ice, sea surface temperature, greenhouse gases and insolation (residual effect) have some impact on the surface 
(a) A-PI (SLP \& Surface wind)

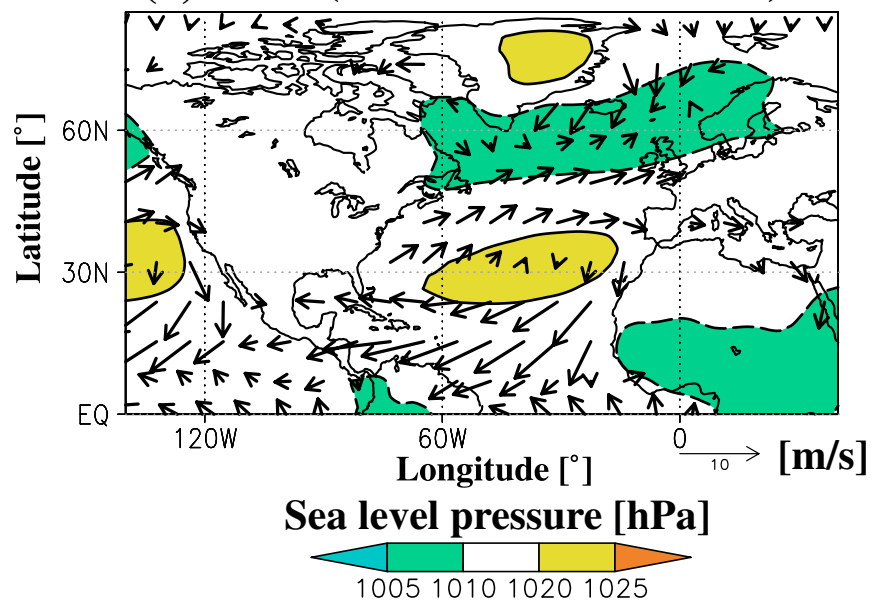

(b) A-NOICE - A-PI

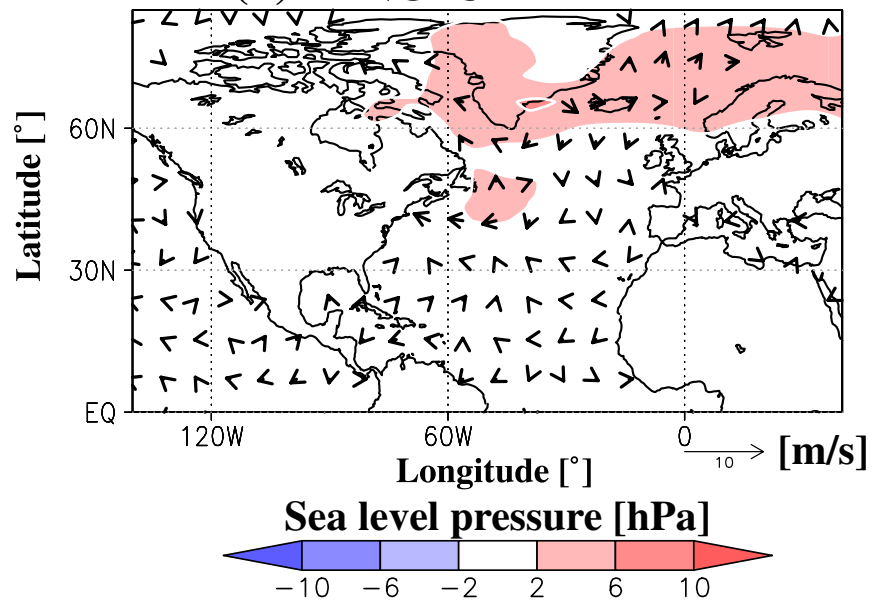

Fig. 3 Surface wind (arrow, $\mathrm{m} / \mathrm{s}$ ) and sea level pressure (SLP, color, hPa) from AGCM experiments. The annual average climatology of (a) A-PI and the differences between A-FULLICE and A-PI

wind, while the impact is relatively small compared to those induced by the glacial ice sheets. However we do not explore them further since they have only a relatively small impact on the AMOC (Sect. 4.1).

Figure 4 shows the general structure of the change in the atmospheric circulation due to the glacial ice sheets. The December-January-February (DJF) average is shown because the change in the wind field reaches its maximum and deep-water formation intensifies before reaching a maximum at the end of this period. Glacial ice sheets induce a cyclonic circulation anomaly downstream of the North American ice sheet and an anti-cyclonic circulation anomaly over the North American ice sheet throughout the troposphere (e.g. Pausata et al. 2011); these anomalies shift westward with height (Löfverström et al. 2015). This is mainly induced by the topography of the North American ice sheet (Fig. 5, e.g. Cook and Held 1988, see also,
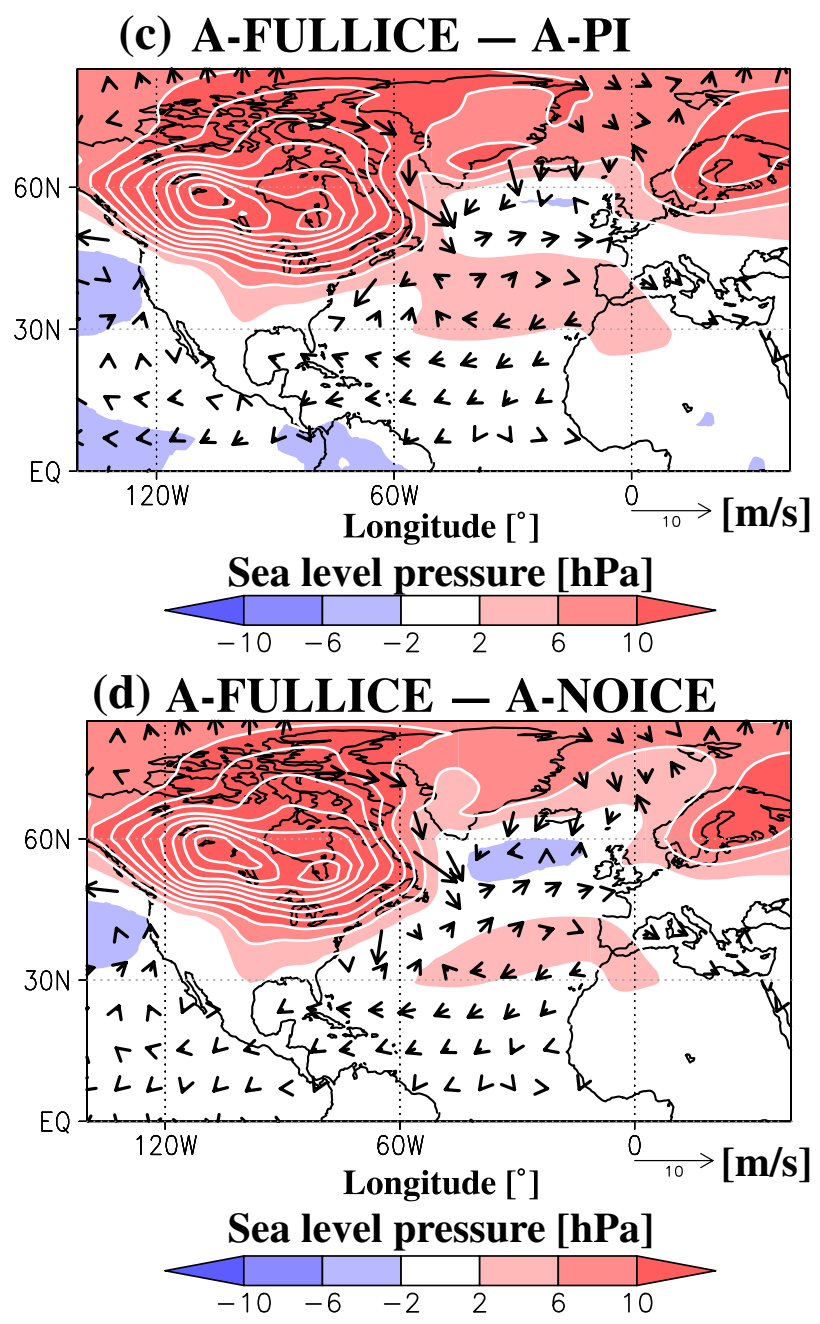

(b), A-NOICE and A-PI (c residual effect) and A-FULLICE and A-NOICE (d ice sheet effect) are shown

1992; Hoskins and Karoly 1981; Held 1983; Trenberth and Chen 1988; Ringler and Cook 1997; Liakka et al. 2012 for the atmospheric response to a large orographic forcing). However, other factors, such as surface cooling over the ice sheet, also play an important role (Cook and Held 1988; Ringler and Cook 1999; Liakka 2012; Löfverström et al. 2014). Associated with the stationary wave field, the westerlies also intensify throughout the troposphere in the North Atlantic (Li and Battisti 2008; Merz et al. 2015).

The influence of the Eurasian ice sheet is small compared to that of the North American ice sheet, although it has a substantial effect over the Norwegian Sea, where a strong southwesterly wind anomaly is induced. This is associated with a high-pressure anomaly over the Eurasian ice sheet. Comparison of A-EUFULL and A-FLATICE shows that this high-pressure anomaly is induced by the topography of the Eurasian ice sheet. However, unlike the 


\section{A-NOICE}

(a) SLP \& Surface wind

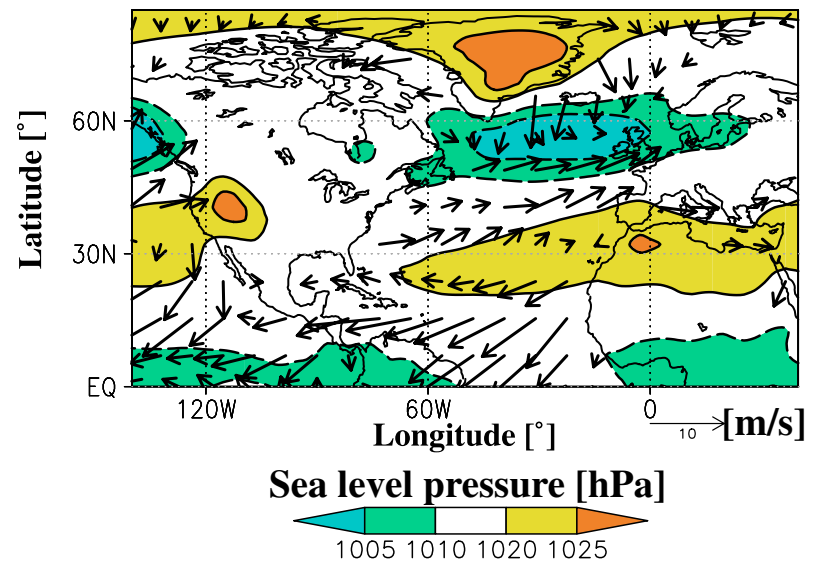

(b) $\mathrm{Z} *$ \& 500hPa zonal wind

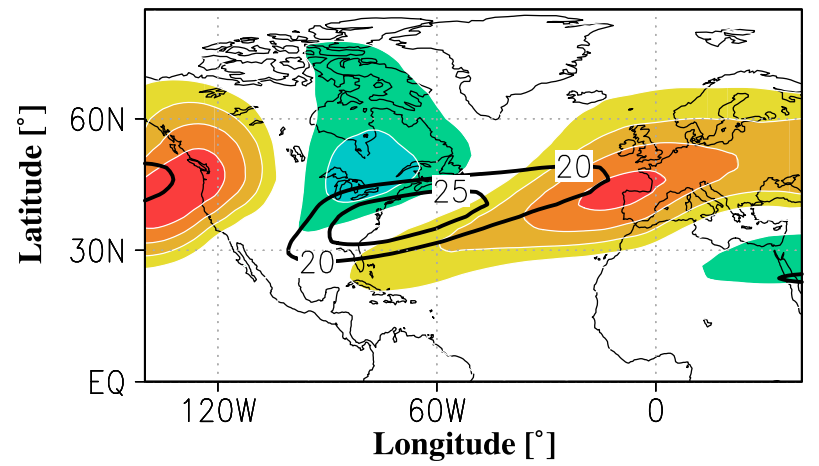

Zonal asymmetric geopotential height $[\mathrm{m}]$

\section{A-FULLICE - A-NOICE}

\section{(c) SLP \& Surface wind}

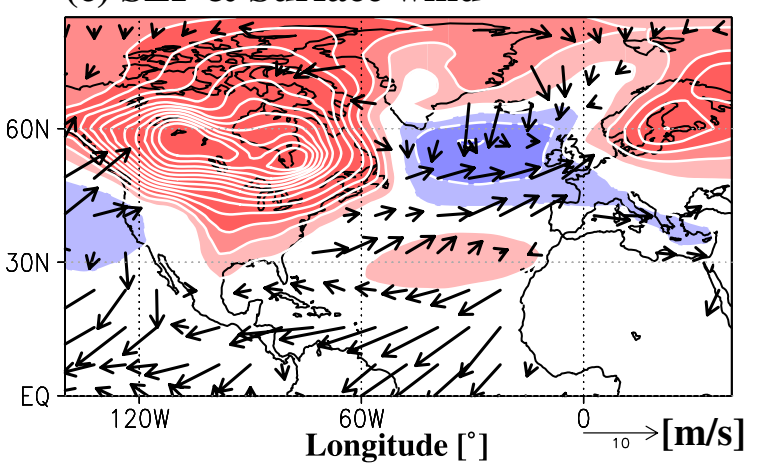

Sea level pressure $[\mathrm{hPa}]$

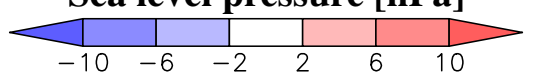

(d) $\mathrm{Z}^{*} \& 500 \mathrm{hPa}$ zonal wind

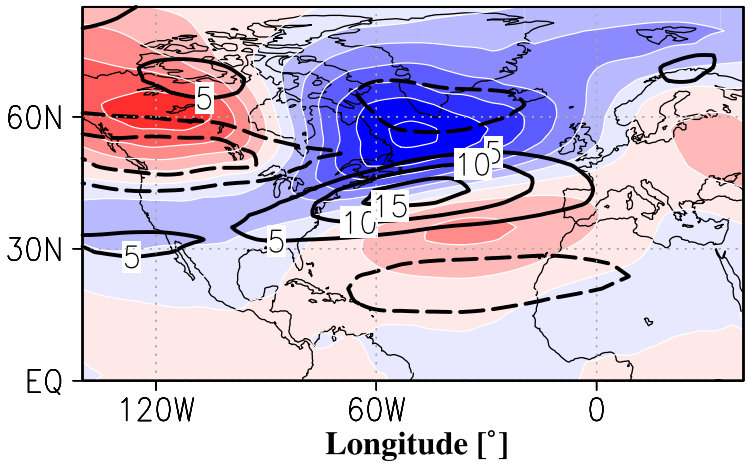

Zonal asymmetric geopotential height [m]

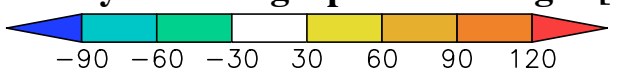

Fig. 4 General structure of glacial ice sheet induced circulation change throughout the troposphere. DJF average is shown. Climatology from A-NOICE is shown on the left and glacial ice sheet effect is shown on the right. Top figures $10 \mathrm{~m}$ height wind (arrow, $\mathrm{m} / \mathrm{s}$ ) and sea level pressure (SLP: contour and color, hPa). Bottom figures

North American ice sheet, the anomaly is confined near the surface, which is perhaps associated with the small size of the ice sheet. This suggests the importance of analyzing both the changes in the wind field at the surface and in the free troposphere, since it is difficult to estimate changes in the former by only looking at the latter (Fig. 5).

\section{Results from the OGCM}

In this section, we first identify the important factor for the intensification of the AMOC through modification of the surface wind stress by using the wind field from the AGCM experiments in the previous section (Tables 3,4). Then we investigate how the wind change intensifies the AMOC.
$500 \mathrm{hPa}$ eddy geopotential height (color, anomaly from the zonal mean, $\mathrm{m}$ ) and $500 \mathrm{hPa}$ zonal wind (contour, $\mathrm{m} / \mathrm{s}$ ). For the SLP anomaly field, regions where the anomaly is outside the range $-2 \mathrm{hPa}$ to $2 \mathrm{hPa}$ are shaded. Contour interval is $4 \mathrm{hPa}$, starting from $-2 \mathrm{hPa}$ to $2 \mathrm{hPa}$

\subsection{Influence on the AMOC}

Using the wind stress from the AGCM sensitivity experiments, we run the OGCM under the glacial thermal and Preindustrial freshwater (E-P-Runoff) conditions (O-FULLICE, O-NOICE and O-HEAT; in O-FULLICE, winds from A-FULLICE are applied, in O-NOICE, winds from A-NOICE are applied and in O-HEAT, winds from A-PI are applied). As a result, we find that the glacial ice sheet effect, which is deduced from the difference between O-FULLICE and O-NOICE, plays an important role in intensifying the AMOC (an increase of 17.0 Sv compared to O-NOICE). By applying the wind stress from A-NAFULL and A-EUFULL to the OGCM (O-NAFULL and O-EUFULL, respectively), the effect of the wind from 
(a) A-FULLICE - A-FLATICE (Topography effect)

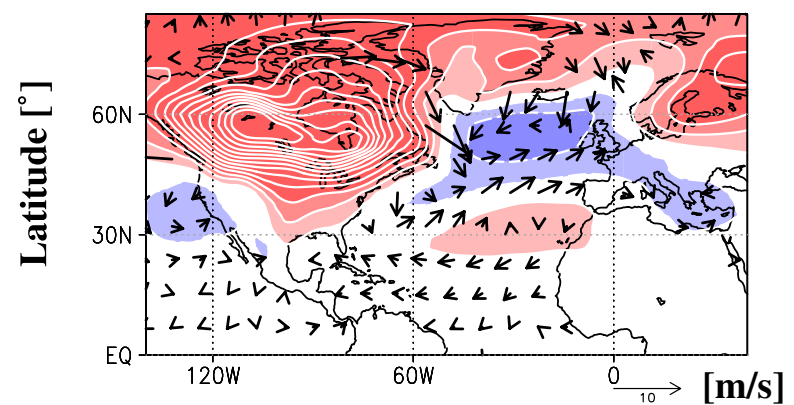

(b) A-FLATICE - A-NOICE (Albedo effect)

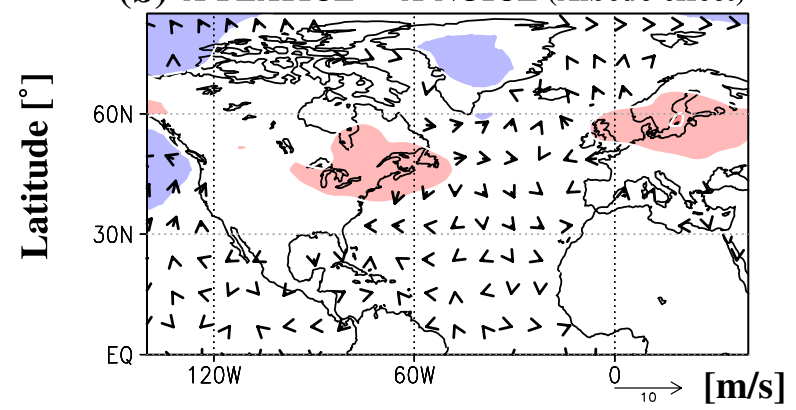

(c) A-NAFULL - A-NOICE (North American effect)

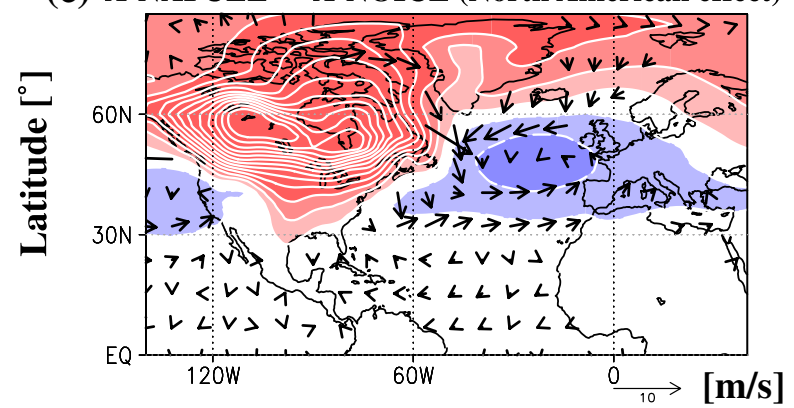

(d) A-EUFULL - A-NOICE (Eurasian effect)

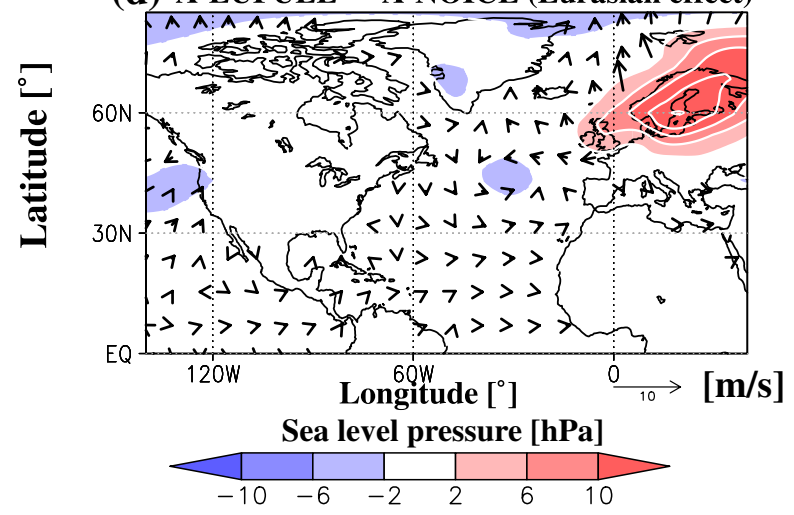

Fig. 5 Decomposition of the glacial ice sheet effect into topography, albedo, North American and Eurasian effect. DJF average is shown. Left figures $10 \mathrm{~m}$ height wind (arrow, $\mathrm{m} / \mathrm{s}$ ) and sea level pressure (SLP: contour and color, hPa). Right figures $500 \mathrm{hPa}$ eddy geopotential height (color anomaly from the zonal mean, m) and $500 \mathrm{hPa}$

\section{(e) A-FULLICE - A-FLATICE (Topography effect)}

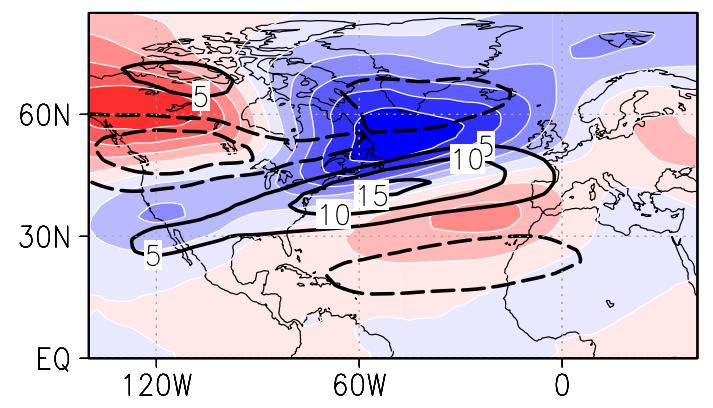

(f) A-FLATICE - A-NOICE (Albedo effect)

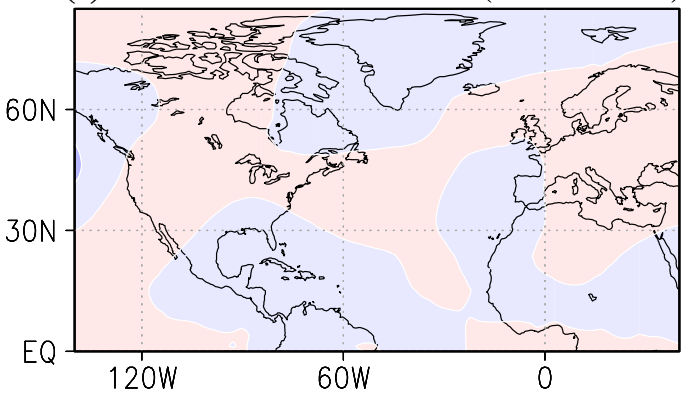

(g) A-NAFULL - A-NOICE (North American effect)

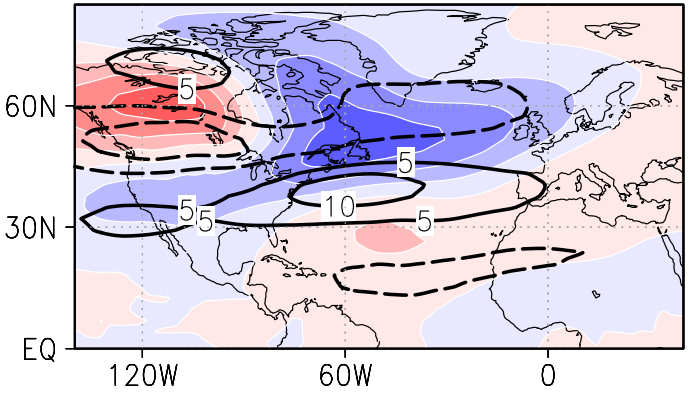

(h) A-EUFULL - A-NOICE (Eurasian effect)

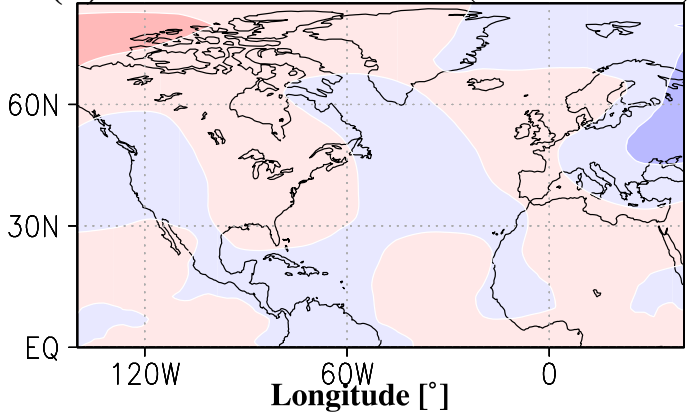

Zonal asymmetric geopotential height $[\mathrm{m}]$

zonal wind (contour, $\mathrm{m} / \mathrm{s}$ ). For the SLP anomaly field, regions where the anomaly lies outside the range -2 to $2 \mathrm{hPa}$ are shaded. Contour interval is $4 \mathrm{hPa}$, starting from $-2 \mathrm{hPa}$ and $2 \mathrm{hPa}$. Note that a different contour interval is used for the albedo and Eurasian effects in the right figures since their effect were especially small 
individual glacial ice sheets is further investigated. Results reveal that both of the ice sheets play an important role in intensifying the AMOC, while the impact of the North American ice sheet is larger (compared to O-NOICE, there is an increase of $14.5 \mathrm{~Sv}$ in O-NAFULL and an increase of 13.1 Sv in O-EUFULL, respectively, see Tables 3, 4). On the other hand, the modification of the wind from A-PI to A-NOICE has only a relatively small impact on the AMOC (an increase of 3.7 Sv in O-NOICE compared to O-HEAT). These experiments demonstrate that the glacial ice sheets, especially the North American ice sheet, play an important role in modifying the AMOC through surface wind.

In order to assess the importance of the separate localities within the North Atlantic, which was unclear in the previous studies (OHA12, Muglia and Schmittner 2015), we apply regional changes (differences between A-FULLICE and A-NOICE) to the wind field in the low latitudes (O-LOW), mid-latitudes (O-MIDDLE) and high latitudes $(\mathrm{O}-\mathrm{HIGH})$ of the North Atlantic. As a result, we find that the AMOC drastically intensifies only when the wind field is modified at mid and high latitudes (compared to O-NOICE, we see an increase of $8.9 \mathrm{~Sv}$ in O-HIGH, an increase of 14.1 Sv in O-MIDDLE and an increase of $0.2 \mathrm{~Sv}$ in O-LOW, see Table 5). From these experiments, we identify the North Atlantic mid-high latitudes as a key region, with the mid-latitudes being of primary importance. Note that we also conduct an experiment, which we apply regional changes to the winds in the Southern Hemisphere, though the impact on the AMOC is small (an increase of $0.4 \mathrm{~Sv}$ compared to O-NOICE).

The drastic change in the AMOC is accompanied by a shift in the region of NADW formation (see Fig. 6 and Kageyama et al. 2009). In the weak AMOC cases, the production of the NADW is confined to the center of the subpolar gyre (O-NOICE) or even ceases (O-HEAT). On the other hand, in the strong AMOC cases, NADW formation also takes place outside or at the rim of the subpolar gyre (O-FULLICE, O-NAFULL, O-EUFULL, O-HIGH and

Table 5 The maximum value of the AMOC obtained from additional OGCM sensitivity experiments, in which we applied changes to the wind field regionally, is shown

\begin{tabular}{lll}
\hline Exp name & $\begin{array}{l}\text { Region where A-FULLICE wind } \\
\text { is applied }\end{array}$ & $\begin{array}{l}\text { AMOC } \\
\max \\
\text { (Sv) }\end{array}$ \\
\hline O-HIGH & $0^{\circ}-360^{\circ}, 65^{\circ} \mathrm{N}-90^{\circ} \mathrm{N}$ & 17.3 \\
O-MIDDLE & $80^{\circ} \mathrm{W}-0^{\circ}, 30^{\circ} \mathrm{N}-65^{\circ} \mathrm{N}$ & 22.5 \\
O-LOW & $80^{\circ} \mathrm{W}-0^{\circ}, 0^{\circ} \mathrm{N}-30^{\circ} \mathrm{N}$ & 8.6 \\
\hline
\end{tabular}

Regional changes in the wind stress between A-FULLICE and A-NOICE are superimposed to A-NOICE wind field and then applied to the OGCM. Therefore these results should be compared with O-NOICE
O-MIDDLE). Note that the AMOC can become strong, even if the NADW formation does not occur north of the Greenland-Iceland-Scotland ridge (Fig. 6). This is somewhat different from OHA12, who showed that, under Preindustrial wind conditions, the increase in global cooling triggers a large weakening of the AMOC by preventing NADW formation in the Greenland-Iceland-Norwegian Seas. This suggests that stronger wind over the North Atlantic can generate a vigorous AMOC with NADW formation south of the Greenland-Iceland-Scotland ridge. Note also that, although the depth of the NADW cell generally increases as the AMOC strengthens, the depth can differ substantially with a similar strength (Supplementary Fig. 2, e.g. O-NAFULL and O-EUFULL). This may have some implications on our understanding of past changes in the deep ocean, for example a vigorous, though shallow AMOC (e.g. Lippold et al. 2012). However, detailed analyses on these topics are not covered here as we are focussing on how the glacial ice sheets intensify the AMOC. These will be reported elsewhere.

\subsection{Wind stress change in the North Atlantic and its effect on the AMOC}

The mechanism by which the North Atlantic mid-latitude and high latitude winds intensify the AMOC is investigated in this section. For this purpose, the annual mean wind stress and wind stress curl is shown as it is directly related to the wind-driven ocean circulation and sea ice transport in the North Atlantic (Fig. 7). In A-NOICE, the wind stress curl is generally positive north of $50^{\circ} \mathrm{N}$ and negative south of $50^{\circ} \mathrm{N}$, which is associated with the Icelandic Low and Azores High. These mainly drive the subpolar and subtropical gyres, respectively. From the anomaly field (Fig. 7b), it is clear that the glacial ice sheet, especially the topography effect of the North American ice sheet (Fig. 5), intensifies the background wind stress curl by strengthening the Icelandic Low. The high-pressure anomaly induced over the North American continent also contributes to the increase in the positive wind stress curl by enhancing the northwesterly wind near the Labrador Sea. Quantitatively speaking, the zonal mean positive wind stress curl over the Atlantic basin doubles in magnitude north of $45^{\circ} \mathrm{N}$ (Fig. 7c). South of $40^{\circ} \mathrm{N}$, the negative wind stress curl increases by a factor of 1.5 compared to A-NOICE. At high latitudes, the glacial ice sheet enhances the northwesterly wind at Baffin Bay and the northerly wind along the east coast of Greenland to the Irminger Sea, and it induces southwesterly wind in the Norwegian Sea. The enhanced cyclonic circulation in the Norwegian Sea results in an increase in the positive wind stress curl of that region. Overall, the glacial ice sheets intensify A-NOICE wind stress curl over the North Atlantic. 

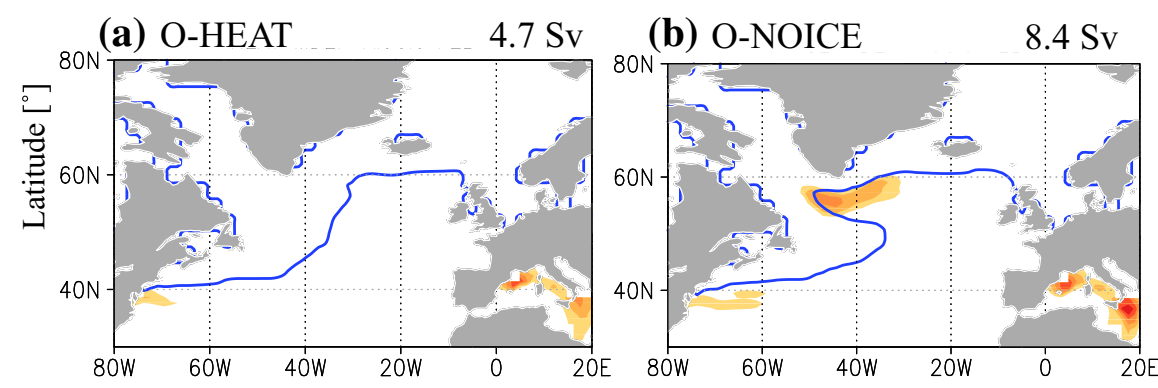

(c) O-FULLICE

$25.4 \mathrm{~Sv}$

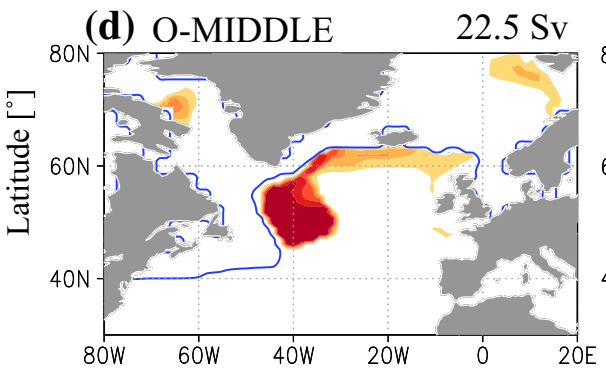

(e) $\mathrm{O}-\mathrm{HIGH}$

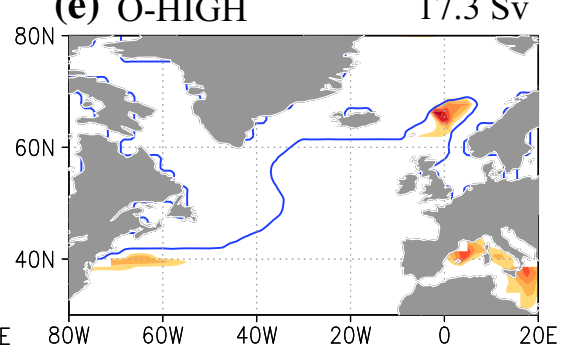

(i) O-EUFULL

$21.5 \mathrm{~Sv}$

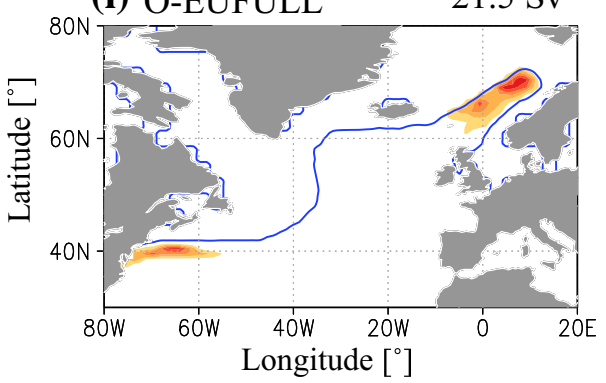

Longitude $\left[{ }^{\circ}\right]$

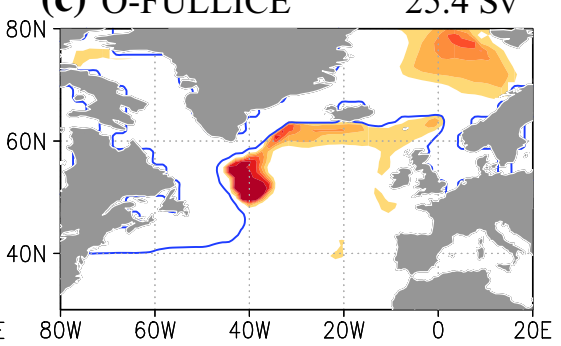

(f) O-NAFULL

$22.9 \mathrm{SV}$

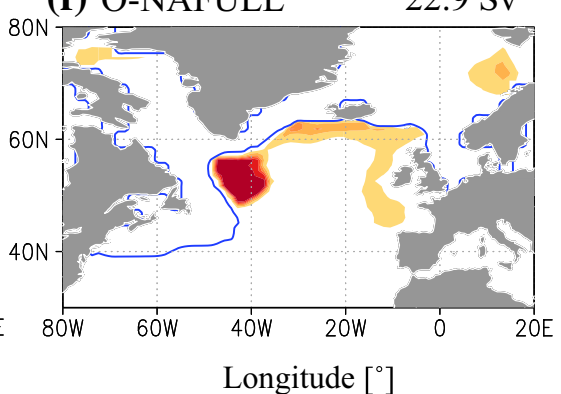

Mixed layer depth [m]

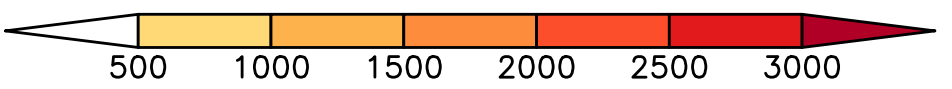

Fig. 6 Region of NADW formation (color February mixed layer depth, $\mathrm{m}$ ) and February $50 \%$ sea ice concentration (bounded by blue line) for a O-HEAT, b O-NOICE, c O-FULLICE, d O-MIDDLE, e

In order to clarify the direct impact of wind change on the ocean and the mechanism, we analyzed the difference between the ocean properties of O-FULLICE and O-NOICE (Supplementary Figs. 3, 4 and 5). However, it was difficult to assess the direct impact of the wind change on the oceanic properties because they are also greatly modified by the drastic changes in the AMOC and the NADW formation region (e.g. Oka et al. 2001; Montoya et al. 2011). Therefore, in order to explore the direct impact of the wind forcing on the oceanic properties and its mechanism in detail, we vary the wind stress linearly from A-NOICE to A-FULLICE globally and calculate the quasi-equilibrium AMOC for each individual experiment. These sets of experiments are named O-LINEAR. Similar experiments were conducted in previous studies (Montoya and Levermann 2008; Saenko 2009a) to explore the impact of changes in the wind on the oceanic properties and the AMOC. The wind stress applied in each experiment is as follows:

Wind stress $=(1-\alpha) \times A \_N O I C E+\alpha \times A \_F U L L I C E$.
$\mathrm{O}$-HIGH, f O-NAFULL and $\mathbf{g} \mathrm{O}-\mathrm{EUFULL}$. Value shown in the upper right corner in each panel indicates the maximum strength of the AMOC

Here, $\alpha$ denotes a wind stress factor and ranges from 0 to 1. When $\alpha=1(\alpha=0)$, the wind stress is identical to A-FULLICE (A-NOICE). Therefore, as the factor increases, the wind stress varies from A-NOICE to A-FULLICE. We use the last year of O-NOICE as initial conditions for these sensitivity experiments. The results of O-LINEAR experiments are summarized in Fig. 8. The AMOC intensifies abruptly at $\alpha=0.27$, after a gradual increase. This abrupt intensification is associated with the initiation of NADW formation outside or at the rim of the subpolar gyre and causes the changes in the oceanic properties (Supplementary Figs. 6, 7 and 8). After the transition, the AMOC responds linearly to a gradual increase in the wind forcing. Thus, the initiation of the new NADW formation region amplifies the strengthening of the glacial AMOC due to the glacial ice sheet wind. Therefore, by analyzing the difference in the oceanic properties of O-NOICE $(\alpha=0)$ and $\alpha=$ 0.25 experiment (prior to the abrupt intensification in the AMOC), we can investigate the direct impact of changes in 
(a) A-NOICE

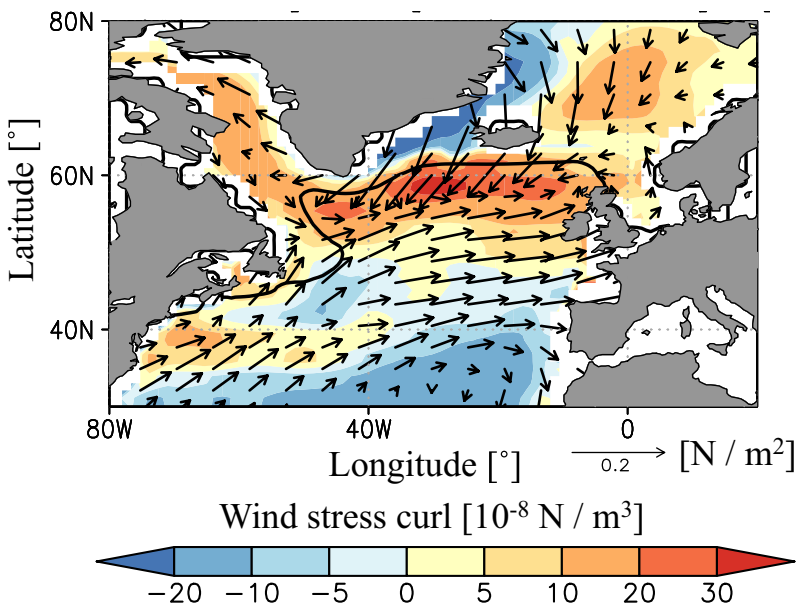

(c) Zonal mean wind stress curl

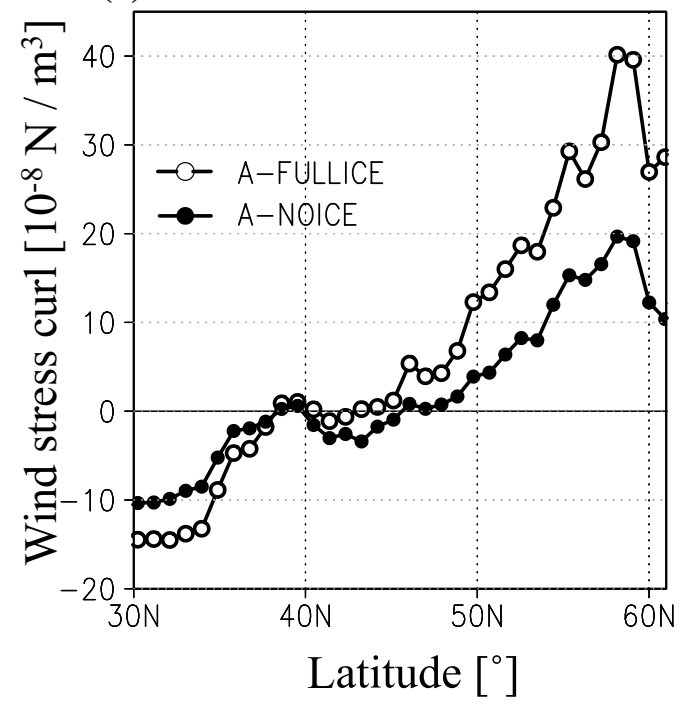

Fig. 7 Annual mean surface wind stress $\left(\right.$ arrow, N/m $\mathrm{m}^{2}$ ) and the wind stress curl (color, $\left.10^{-8} \mathrm{~N} / \mathrm{m}^{3}\right)$ for a A-NOICE and $\mathbf{b}$ the glacial ice sheet effect (A-FULLICE-A-NOICE). c Wind stress curl zonally

the wind on the oceanic properties and also the cause of the shift of the NADW formation region.

Differences in the zonally averaged potential density, salinity and potential temperature in the Atlantic basin of O-NOICE and $\alpha=0.25$ experiment (Fig. 9) are analyzed because the shift in the region of the NADW formation is related to the changes in the surface water properties of the northern North Atlantic (e.g. Montoya and Levermann 2008). From Fig. 9, it is clear that the sea surface density increases at mid-high latitudes and thus the stratification weakens before the large abrupt increase in the AMOC. This density increase is primarily attributed to an increase in surface salinity, while the increase in temperature has only a small impact on the surface density. Therefore, the (b) Ice sheet effect (A-FULLICE - A-NOICE)

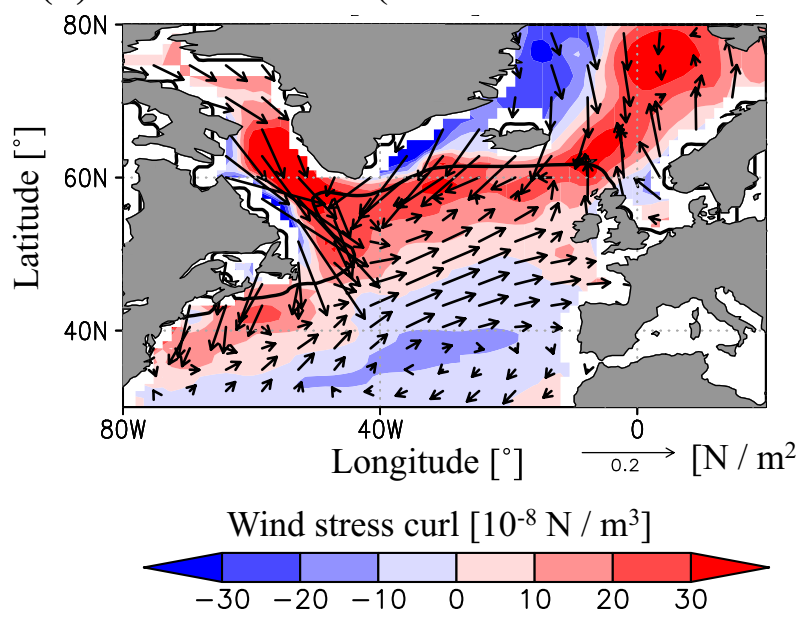

averaged over the Atlantic basin for A-NOICE (black circle) and A-FULLICE (white circle). In $\mathbf{a}$ and $\mathbf{b}$, the black line indicates annual mean $50 \%$ sea ice concentration in O-NOICE

large abrupt increase in the AMOC can be triggered as a result of the increase in salinity at the surface of the northern North Atlantic. This increase in salinity can be attributed to either wind-driven oceanic circulation (Oka et al. 2001; Timmerman and Goose 2004; Montoya and Levermann 2008; Montoya et al. 2011; Zhang et al. 2014) or/ and wind-driven sea ice transport (Born et al. 2010; Zhong et al. 2011; Zhu et al. 2014; Zhang et al. 2014).

The increase in oceanic salt transport appears important for the large increase in surface salinity (Figs. 10, 11). Figure 10 shows the surface salinity and barotropic streamfunction, which defines the subpolar and subtropical gyres, and Fig. 11 shows vertical-latitudinal crosssection of isopycnal surfaces zonally averaged over the 


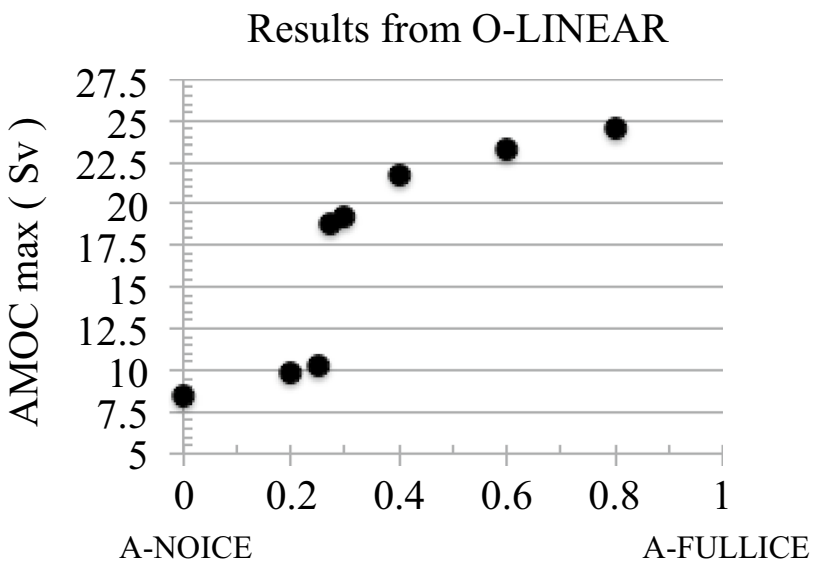

a: wind anomaly factor

Fig. 8 Results from linear sensitivity experiments (O-LINEAR). Scatter plot of AMOC strength and wind stress anomaly factor. Experiments are initialized from O-NOICE. An abrupt increase in the AMOC occurs at $\mathrm{a}=0.27$

subpolar gyre $\left(45^{\circ} \mathrm{W}-25^{\circ} \mathrm{W}\right)$. Figure 11 illustrates the exposure of the subsurface warm, saline water to the sea surface due to Ekman upwelling driven by the positive wind stress curl in this region (e.g. Marshall and Schott
1999; Kuhlbrodt et al. 2007; Montoya et al. 2011). In O-NOICE, saline water is transported horizontally/vertically from the subtropics/subsurface by the wind-driven gyre/Ekman upwelling. This maintains the salinity maximum at high latitudes, as there is no minimum in the freshwater flux in this region (not shown). Note that the subpolar gyre does not extend into the Norwegian Sea because the production of NADW is absent in this region as a result of the sea ice expansion due to surface cooling (OHA12). As the surface wind strengthens due to the glacial ice sheet, both the subpolar and subtropical gyres are enhanced (Fig. 10b). This strengthening of the gyres enhances horizontal transport of salt (Oka et al. 2001; Timmerman and Goose 2004; Montoya and Levermann 2008), thus contributing to the increase in surface salinity of the northern North Atlantic. The strengthening of the surface wind also enhances the vertical salt transport. This is demonstrated in Fig. 11b-the glacial ice sheet wind enhances the upwelling of the subsurface saline water to the surface, which, in turn, triggers the convective mixing. This further mixes the saline subsurface water with fresher surface water and increases the surface salinity (Zhong et al. 2011). Thus, the strengthening of both horizontal and vertical oceanic salt transport plays an important role. (a) Density: O-NOICE

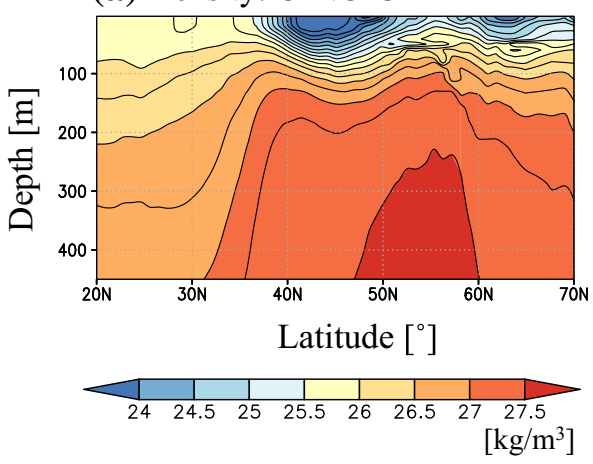

(d) Density: $\mathrm{a}=0.25$ - O-NOICE

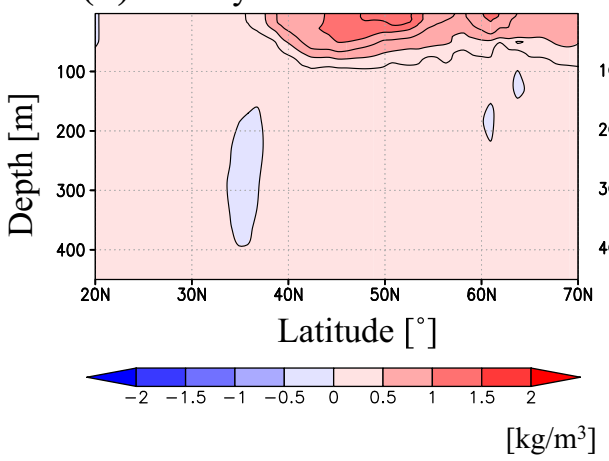

(b) Salinity: O-NOICE

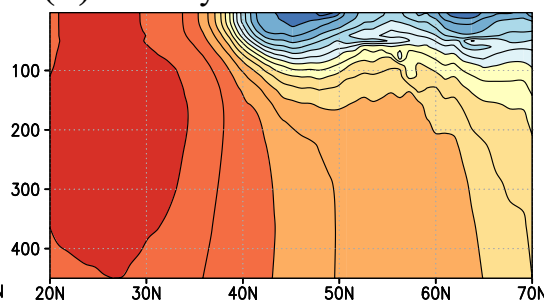

Latitude $\left[{ }^{\circ}\right]$

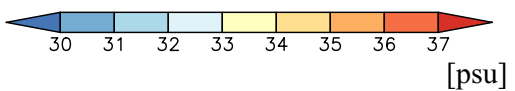

(e) Salinity: $\mathrm{a}=0.25-\mathrm{O}-\mathrm{NOICE}$

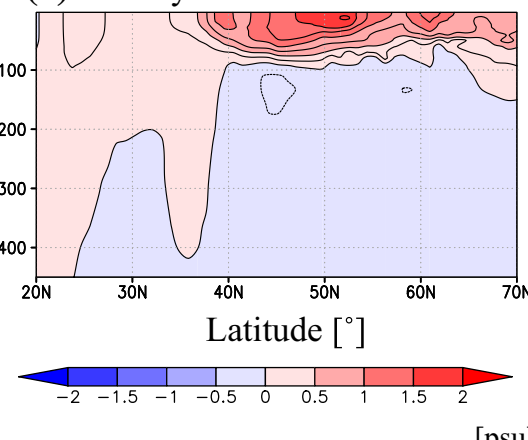

(c) Temperature: O-NOICE

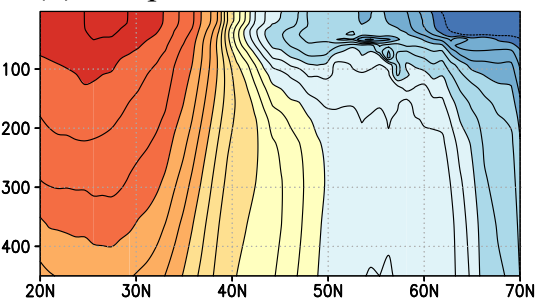

Latitude $\left[{ }^{\circ}\right]$

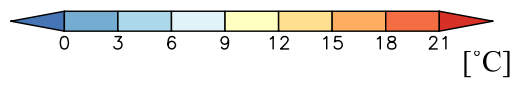

(f) Temperature: $\mathrm{a}=0.25-\mathrm{O}-\mathrm{NOICE}$

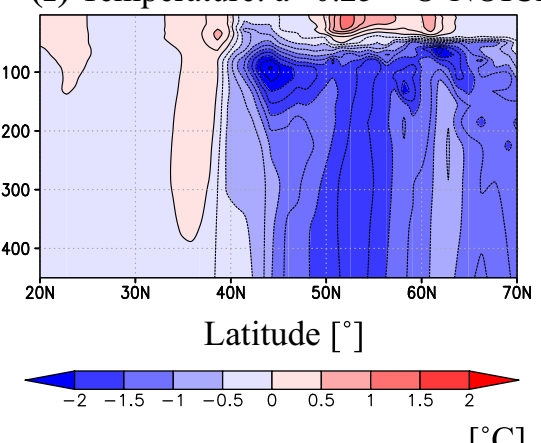

Fig. 9 a Potential density, $\mathbf{b}$ salinity and $\mathbf{c}$ potential temperature, zonally averaged across the Atlantic basin in O-NOICE $(a=0)$, and $\mathbf{d}$, e, $\mathbf{f}$ the differences between their values in $\mathrm{a}=0.25$ and $\mathrm{O}-\mathrm{NOICE}$ 


\section{Surface salinity [psu] and Barotropic streamfunction [Sv]}

(a) O-NOICE $(\mathrm{a}=0)$

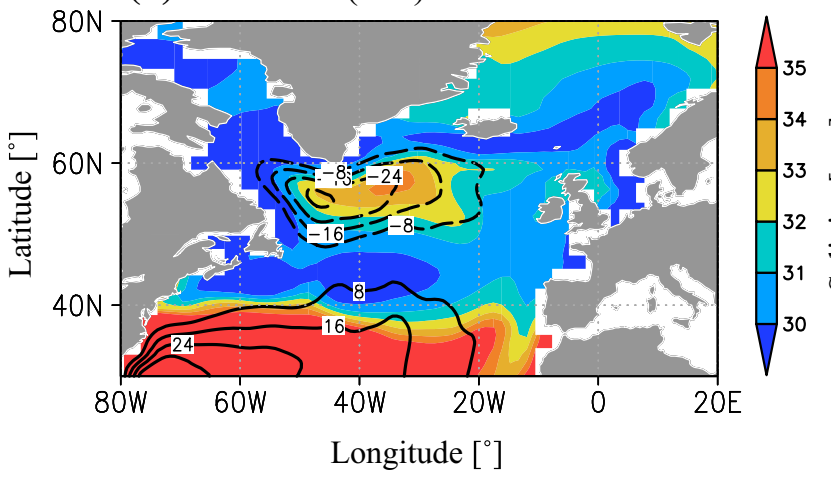

(b) $\mathrm{a}=0.25$ - O-NOICE

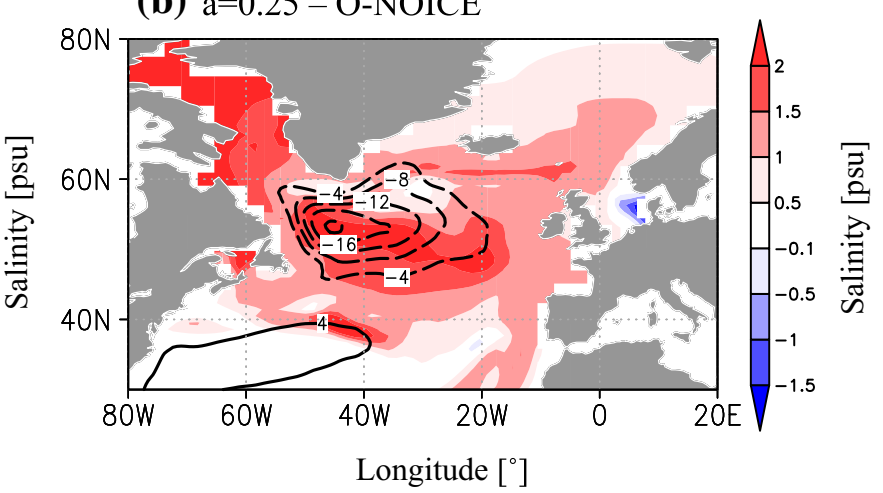

Fig. 10 Surface salinity (color, psu) and baratropic streamfunction (contour, $\left.\mathrm{m}^{2} / \mathrm{s}\right)$ before large increase in AMOC for a O-NOICE $(\mathrm{a}=0)$ and $\mathbf{b}$ the differences between their values in $\mathrm{a}=0.25$ and O-NOICE

Fig. 11 Vertical-latitudinal cross-section of potential density $\left(\mathrm{kg} / \mathrm{m}^{3}\right)$, zonally averaged over $45^{\circ} \mathrm{W}-25^{\circ} \mathrm{W}$. a O-NOICE $(\mathrm{a}=0), \mathbf{b} \mathbf{a}=0.25$. This figure illustrates the exposure of the subsurface warm and saline water to the sea surface (outcropping) by the positive wind stress curl in this region (e.g. Montoya et al. 2011)

Potential density (zonally averaged over $45^{\circ} \mathrm{W}-25^{\circ} \mathrm{W}$ )

(a) O-NOICE

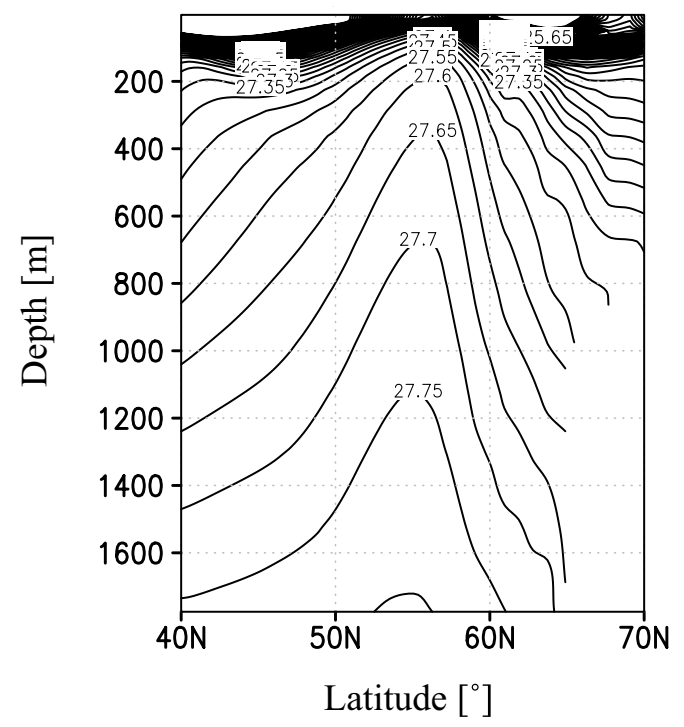

(b) $\mathrm{a}=0.25$

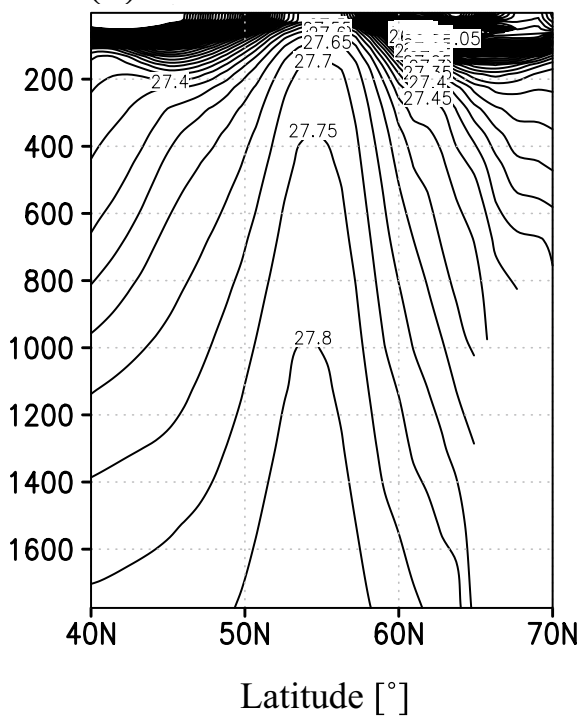

On the other hand, changes in the sea ice transport appear to play an opposite role. Figure 12 shows the sea ice volume transport and sea ice formation rate superimposed on the annual mean $10 \%$ sea ice concentration. In O-NOICE, sea ice forms near the continental shelf, is transported mainly by the wind field (Steele et al. 1997; Zhu et al. 2014) and melts near the region of NADW formation and at mid-latitudes (e.g. Bitz et al. 2005). In the experiment of $\alpha=0.25$ (Fig. 12b), the glacial ice sheet wind enhances the sea ice transport into the North Atlantic (Fig. 12c), which is induced by intensified northwesterly wind in the Labrador Sea and northerly wind in the Irminger Sea (e.g. Fig. 7b). In particular, the zonally averaged southward sea ice volume transport increases by
$0.06 \mathrm{~m}^{2} \mathrm{~s}^{-1}$ in the Labrador Sea and $0.014 \mathrm{~m}^{2} \mathrm{~s}^{-1}$ in the Denmark Strait compared to O-NOICE. As a result, the area-averaged sea ice melt (negative sea ice growth rate across $70^{\circ} \mathrm{W}-5^{\circ} \mathrm{W}, 40^{\circ} \mathrm{N}-65^{\circ} \mathrm{N}$ ) increases from 0.92 to $1.23 \mathrm{~cm} /$ day. This will reduce the surface salinity and weaken the AMOC (Saenko et al. 2002; Born et al. 2010). However, the fact that the glacial ice sheet wind intensifies the AMOC suggests that the oceanic salt transport processes play the more important role in intensifying the AMOC, which dominates the opposite effect of the sea ice process. (Note that the increase in freshwater transport by sea ice will be partly compensated by a decrease in freshwater transport by liquid water (Saenko et al. 2002), which can be expected from a large increase in salinity at the 
(a) Sea ice formation, sea ice volume transport: O-NOICE

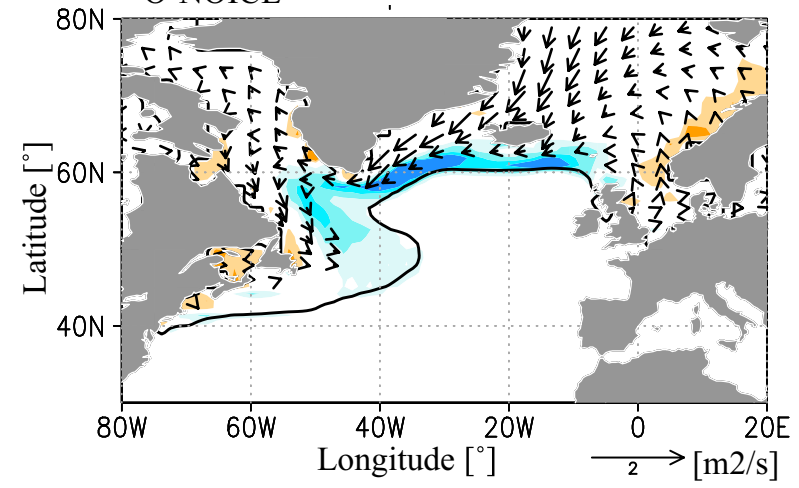

(c) Sea ice concentration, sea ice volume transport: $\mathrm{a}=0.25-\mathrm{O}-\mathrm{NOICE}$

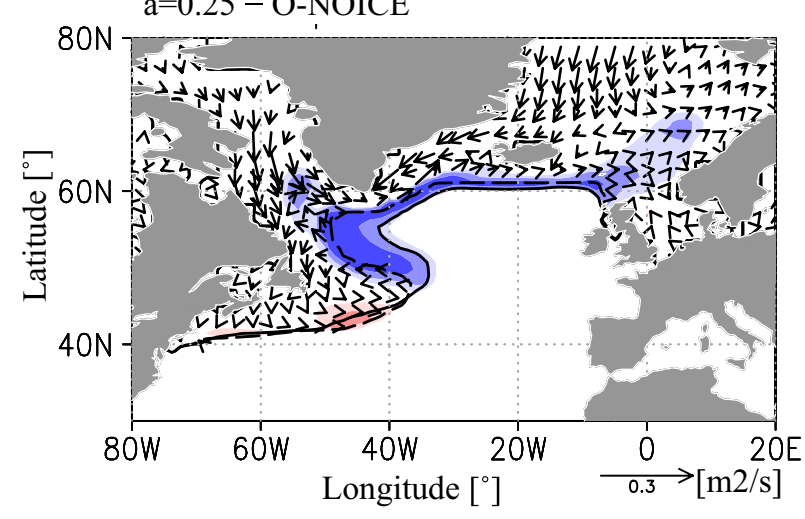

Fig. 12 Change in sea ice before abrupt AMOC change. Annual mean sea ice volume transport (arrow, $\mathrm{m}^{2} / \mathrm{s}$ ), sea ice formation/ melt (color, cm/day) and $10 \%$ sea ice concentration (contour) for a O-NOICE, $\mathbf{b} \mathbf{a}=0.25$. In $\mathbf{c}$, differences in the sea ice volume trans-

Baffin Bay. However changes in sea ice have larger impact on the deep-water formation as they directly affect the deep-water formation region (Born et al. 2010).

Changes in the wind over the Greenland-Iceland-Norwegian Sea also modify the AMOC (O-HIGH, O-EUFULL). In this region, positive wind stress curl is enhanced due to the glacial ice sheet topography (Figs. 5,7) and the Eurasian ice sheet also plays an important role (Fig. 13). The increase in the positive wind stress curl intensifies both the surface cyclonic ocean circulation and the Ekman upwelling (Fig. 14). This enhances horizontal and vertical transport of salt to the surface and thus increases the surface salinity (Fig. 10). In addition, the southwesterly wind stress anomaly exports the sea ice out of the Norwegian Sea and leads to a reduction in sea ice (Fig. 12c). Thus, once the wind forcing becomes sufficiently large, deep-water formation can be initiated in the Norwegian Sea owing to higher surface salinity and a reduced amount of sea ice (Fig. 6c, e, g). As a result, the AMOC exhibits an abrupt intensification (e.g. Fig. 8). Thus, these results show (b) Sea ice formation, sea ice volume transport:
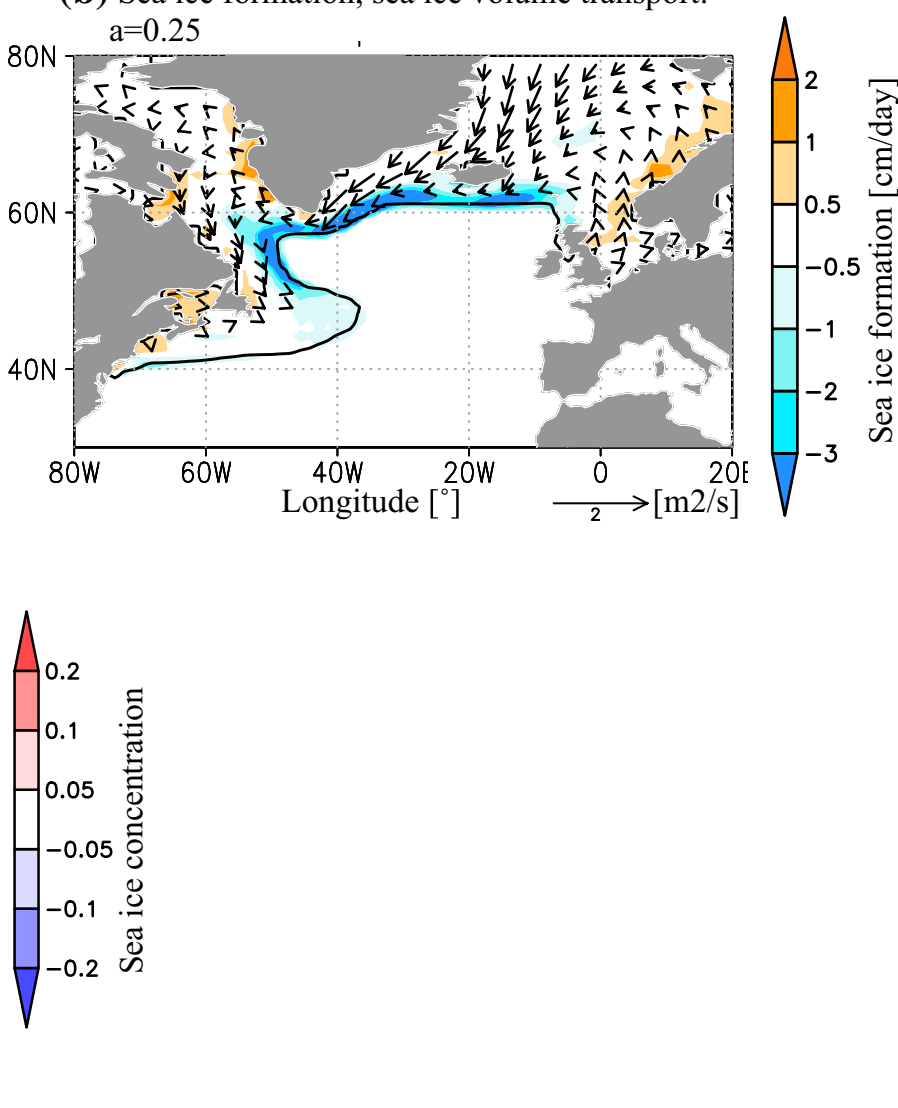

port (arrow) and sea ice concentration (color) between $\mathrm{a}=0.25$ and O-NOICE is shown. Bold and dashed contours indicate the 10\% sea ice concentration (contour) for O-NOICE and $\mathrm{a}=0.25$, respectively

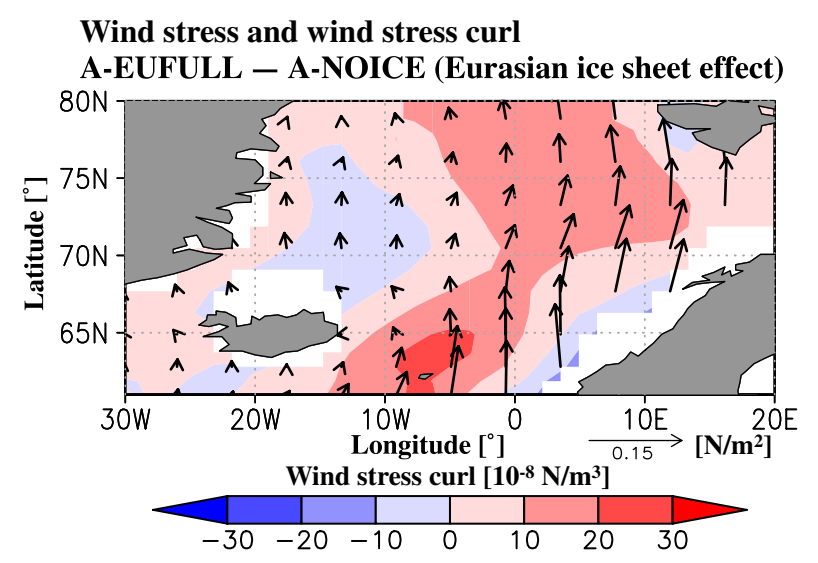

Fig. 13 Annual mean surface wind stress (arrow, N/m²) and the wind stress curl $\left(\right.$ color, $\left.10^{-8} \mathrm{~N} / \mathrm{m}^{3}\right)$ over the Norwegian Sea for the Eurasian ice sheet effect (A-EUFULL-A-NOICE) 
(a) O-NOICE (Horizontal flow \& vertical flow)

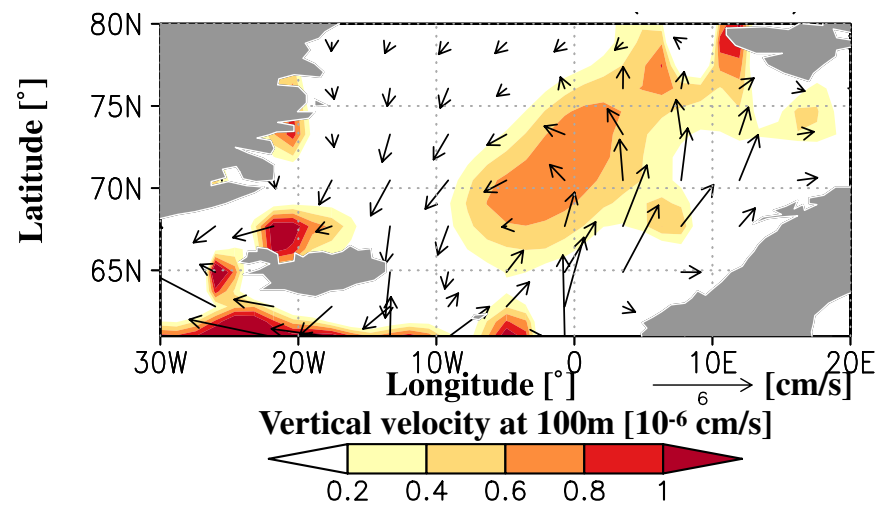

(c) $\mathrm{a}=0.25-\mathrm{O}$-NOICE

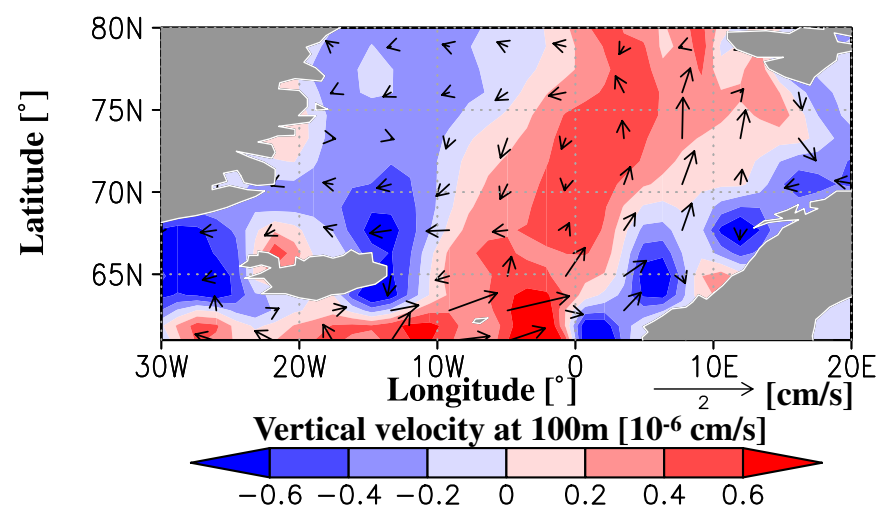

Fig. 14 Change in oceanic circulation before abrupt AMOC change. Annual mean horizontal velocity averaged between the surface and $100 \mathrm{~m}$ depth (arrow, $\mathrm{cm} / \mathrm{s}$ ) and vertical velocity at $100 \mathrm{~m}$

that local changes in surface winds over the Norwegian Sea can trigger drastic changes in the AMOC by directly affecting the deep-water formation in this region.

\section{Discussions}

From a series of sensitivity experiments using the AGCM and the OGCM, we find that the glacial ice sheets cause the AMOC to strengthen by intensifying the atmospheric circulation at the North Atlantic mid- to high latitudes, with the mid-latitudes being of primary importance. For the midlatitude process, our decoupled simulations confirm the importance of increase in wind stress, which has been suggested in previous coupled modelling studies (e.g. Zhang et al. 2014; Gong et al. 2015). Therefore, the mid-latitude process can be considered as a robust and common feature among models. From sensitivity experiments using the AGCM and the OGCM, this intensification of the wind is attributed to the topography effect of the glacial ice sheets, especially that of the North American ice sheet, which is (b) $\mathbf{a}=\mathbf{0 . 2 5}$ (Horizontal flow \& vertical flow)

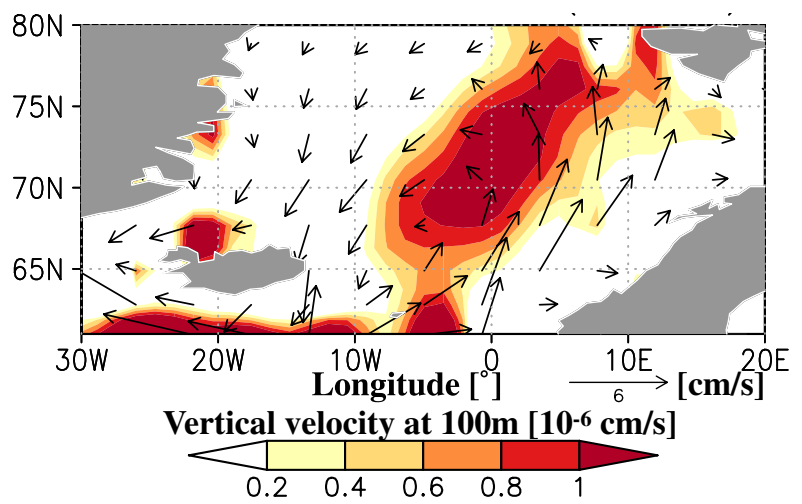

depth (color, $\left.10^{-6} \mathrm{~cm} / \mathrm{s}\right)$ for a O-NOICE, $\mathbf{b}$ a $=0.25$. In c, difference between $\mathrm{a}=0.25$ and $\mathrm{O}-\mathrm{NOICE}$ is shown

consistent with previous atmospheric studies (e.g. Cook and Held 1988; Li and Battisti 2008; Ullman et al. 2014; Löfverström et al. 2014; Merz et al. 2015). Our decoupled simulations also show that the strengthening of the atmospheric cyclonic circulation over the Greenland-IcelandNorwegian Seas can have a large impact on the AMOC. This is related to the initiation of the deep-water formation in the Norwegian Sea (Fig. 6). To our knowledge, the role of high latitude winds related to the ice sheets has not been pointed out in previous coupled modeling studies. AGCM and OGCM sensitivity experiments show that the Eurasian ice sheet plays a role by inducing the southwesterly wind stress anomaly over the Norwegian Sea. However, there are very few studies that explore changes in the wind field over the Norwegian Sea due to the Eurasian ice sheet. Thus, it is difficult to assess the robustness of the high-latitude process. We suggest that model comparison of the wind field in this region is important.

Results from O-FULLICE, O-NAFULL and O-EUFULL show that the responses of the AMOC to wind forcing are highly nonlinear: if they are linear, the sum 
of the wind effects of the North American and Eurasian ice sheets should be similar to that of the full glacial ice sheet. The reason for the nonlinearity of the AMOC can be explained using Fig. 8. This figure shows that changes in the wind forcing can cause a drastic change in the AMOC by triggering an initiation of a new NADW formation region (e.g. Fig. 6). Since all of O-FULLICE, O-NAFULL and O-EUFULL have passed this transition, the AMOC is drastically intensified in these experiments. After passing this threshold, the AMOC responds linearly to a gradual increase in the wind forcing. Thus, the strength of the AMOC in the experiments where the threshold has been passed (e.g. O-NAFULL and O-EUFULL) become similar to one another, compared to those where the threshold has not been passed (e.g. O-NOICE). However, note that the general structure of the AMOC in O-FULLICE is mainly controlled by the North American ice sheet, as the strength of the AMOC, the spatial structure of the NADW cell (Supplementary Fig. 2) and the NADW formation region of O-FULLICE (Fig. 6) is much closer to those of O-NAFULL. This is reasonable considering the larger wind changes due to the North American ice sheet.

In the present study, changes in the wind-driven sea ice transport worked as an effect in weakening the AMOC. This is associated with the increase of sea ice transport into the northern North Atlantic due to the enhanced northerly wind over the Labrador Sea and the Denmark Strait. Since the enhancement of the northerly wind in these regions is a common feature among models (Fig.S1 in Muglia and Schmittner 2015), this effect can be regarded as robust. However, the meridional shift of the westerlies can also greatly affect the wind-driven sea ice process, as suggested by Zhang et al. (2014). In Zhang et al. (2014), the westerlies split into northern and southern branches when they applied glacial ice sheets, resulting in weaker westerlies at their original position. They suggested that this results in a reduction of eastward sea ice transport into the NADW formation region and therefore an intensification of the AMOC. In our case, because the westerlies did not show any meridional shift but only an increase in speed, this effect may be absent. If the westerlies had shifted south (north), this may have led to a reduction (an increase) in eastward sea ice transport to the region of NADW formation, and thus modify the strength (or perhaps the sign) of the sea ice process. Since the meridional shift of the westerlies in response to glacial ice sheets depends on the model (Laîné et al. 2009; Rivière et al. 2010; Hofer et al. 2012; Merz et al. 2015; Beghin et al. 2015) and the configuration of the ice sheets (Kageyama et al. 1999, Li and Battisiti 2008; Laîné et al. 2009; Beghin et al. 2015), the effect of the sea ice process related to the meridional shift of the westerlies should also depend largely on individual simulations. More studies are required to understand the precise role of the sea ice process related to the meridional shift of the westerlies.

The experiments in the present study have been carried out with modern land-sea mask in order to focus on the impact of wind forcing on the AMOC. However, changes in the land-sea mask (e.g. closure of the Bering Strait and shrinking of the Greenland-Icelandic-Norwegian Sea) also have an impact on the freshwater transport (sea ice and liquid water) and the AMOC. In fact, previous studies have shown that the closure of the Bering Strait restricts the Bering throughflow from the Pacific and reduces the transport of sea ice from the Arctic to the Atlantic (e.g. Hasumi 2002; $\mathrm{Hu}$ et al. 2015), while the shrinking of the Greenland-Icelandic-Norwegian Sea restricts the exchange of sea ice and seawater between the Arctic and the GreenlandIcelandic-Norwegian Seas. Thus, these changes in the landsea mask may have an impact on the high-latitude process, which is partly related to the sea ice export out of the Norwegian Sea. Since the expansion of the ice sheet restricts the northward sea ice transport out of the Norwegian Sea by narrowing the pathway into the Arctic, the efficiency of the high latitude wind may change. For the mid-latitude process, it is reasonable to assume that the wind effect is less affected by changes in the land-sea mask because this process is localized in the North Atlantic, away from the large changes in the land-sea mask. This assumption is supported by the fact that the importance of the wind forcing does not depend on the land-sea mask (OHA12, Muglia and Schmittner 2015).

The glacial ice sheet used in the present study (ICE5G) has elevations higher than those of other reconstructions (e.g. ICE-4G, Peltier 1994; PMIP3; Abe-Ouchi et al. 2015). Some studies have shown that the difference in the glacial ice sheet distribution could alter the strength and configuration of the AMOC and sea ice distribution (Justino et al. 2006; Vettoretti and Peltier 2013; Ullman et al. 2014). Hence we conducted additional experiments, in which we applied the PMIP3 ice sheet to assess the impact of changes in the ice sheet on the wind stress in the North Atlantic (Fig. 15). Results show that the cyclonic surface wind weakens at mid-latitudes, while the northwesterly wind strengthens near the Labrador Sea with the PMIP3 ice sheet. This causes a decrease in the zonal mean wind stress curl over the mid-latitudes, though it does not change around $60^{\circ} \mathrm{N}$ as the increase in positive wind stress curl near the Labrador Sea counteracts a decrease in wind stress curl induced by a weaker cyclonic wind field. The weaker cyclonic wind can be attributed to the lower ice sheet configuration (e.g. Zhang et al. 2014), though the mechanism of a stronger northwesterly near the Labrador Sea is not straightforward and that local differences in the ice sheet configuration may be important. However, detailed investigation on the cause of the northwesterly wind stress 
(a) Wind stress: A-PMIP3 - A-FULLICE

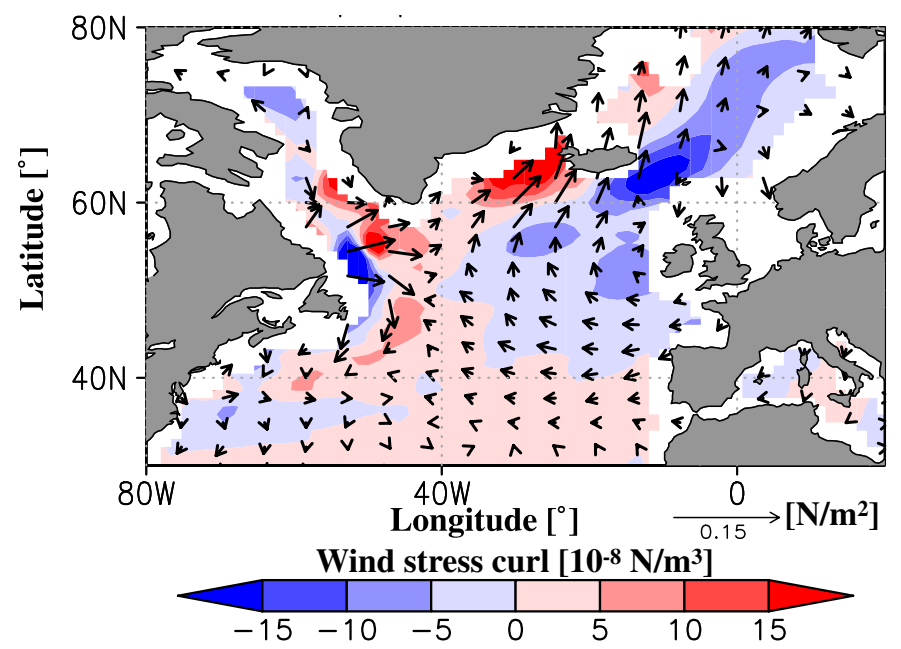

(b) Zonal averaged wind stress curl

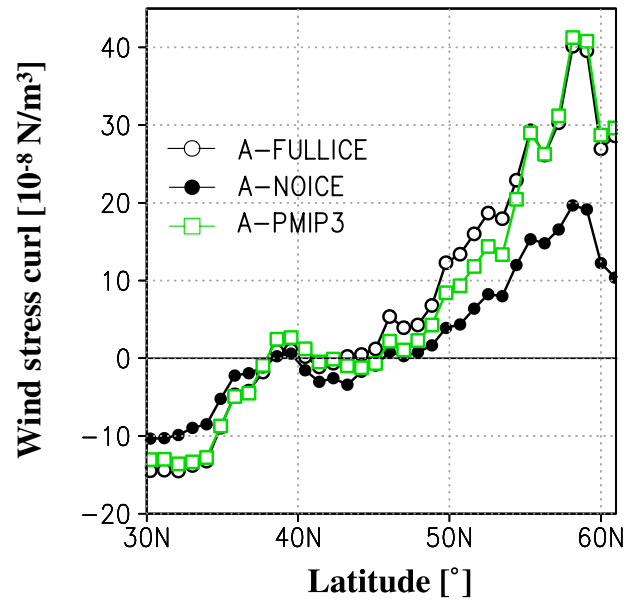

Fig. 15 a Differences in surface wind stress (arrow; $\mathrm{N} \mathrm{m}^{-2}$ ) and wind stress curl (color, $10^{-8} \mathrm{~N} \mathrm{~m}^{-3}$ ) between A-PMIP3, to which we applied the PMIP3 ice sheet (Abe-Ouchi et al. 2015; green contour), and A-FULLICE. b Zonal averaged wind stress curl over the Atlantic basin (unit: $10^{-8} \mathrm{~N} \mathrm{~m}^{-3}$ ). The results from A-NOICE and A-FULLICE are also shown anomaly is beyond the scope of this study. Overall, with respect to mid-latitude wind stress curl, the wind effect on the AMOC is weaker under the PMIP3 ice sheet forcing. Although, reconstructions show both a weaker and stronger AMOC during the LGM, the fact that all of the PMIP3 models show a strong AMOC suggests that more investigations are needed for a future study, for example the processes around the Southern Ocean (e.g. Roche et al. 2012; Kobayashi et al. 2015). Previous studies have suggested the importance of a Southern Ocean process for simulating a weaker AMOC in the LGM simulation, which is related to the production of sea ice and bottom water formation in this region (Stouffer and Manabe 2003; Schmittner 2003; Shin et al. 2003; Liu et al. 2005). Our results also suggest that a weaker wind over the North Atlantic mid-high latitudes or the increase in the sea ice transport into the North Atlantic can contribute towards the weakening of the AMOC. Since ice sheet reconstructions have uncertainties in their height, it may be useful to conduct several ensemble simulations and assess whether the coupled models can reproduce the weak AMOC in their LGM simulations within the uncertainty of the ice sheet reconstructions.

\section{Conclusions}

In this study, we conduct a series of sensitivity experiments using the AGCM and the OGCM decoupled from the AOGCM and investigate the effect of wind change due to the glacial ice sheets on the AMOC and the region where wind change is important in modifying the AMOC. These remained elusive in previous studies. Our main findings are summarized below.

- We show from decoupled experiments (A-FULLICE, A-NOICE, A-PI, O-FULLICE, O-NOICE and $\mathrm{O}$-HEAT) that the surface wind change induced by the glacial ice sheets plays a crucial role in intensifying the AMOC and maintaining a strong AMOC.

- From sensitivity experiments in which we modify the wind field regionally or to which we apply wind change due to individual ice sheets (O-HIGH, O-MIDDLE, O-LOW, O-NAFULL and O-EUFULL), we find the wind change at North Atlantic mid-high latitudes to be crucial, with the mid-latitudes being of primary importance. In this region, surface wind stress and wind stress curl are enhanced due to the glacial ice sheet topography effect, especially that of the North American ice sheet. This is associated with an intensified Icelandic Low and a high surface pressure anomaly over northern North America, which are found throughout the troposphere. We also find that the Eurasian ice sheet can have an impact on the AMOC by inducing a southwesterly wind stress anomaly over the Norwegian Sea, which directly affects the deep-water formation in this region.

- The intensified wind enhances the AMOC by strengthening the wind-driven ocean circulation and, thus, the salt transport. Changes in the wind also increase the sea ice transport into the North Atlantic, which has as an opposite effect on the AMOC by increasing the sea ice melt at the region of NADW formation near the Labrador Sea. However, this effect is minor com- 
pared to those of the salt processes in our simulation (O-LINEAR). We suggest that a weaker wind over the mid-high latitudes and/or stronger sea ice transport into the North Atlantic may help to produce a weak AMOC in coupled model simulations.

\begin{abstract}
Acknowledgements We thank three anonymous reviewers for their constructive comments that helped to significantly improve this study. The model simulations were performed on Earth Simulator 2 at JAMSTEC and on HITACHI SR16000 at the Information Technology Center, The University of Tokyo. Requests for numerical data should be addressed to S. Sherriff-Tadano (email: tadano@aori.u-tokyo. ac.jp). GrADS was used to create figures. This study was supported by Program for Leading Graduate Schools, MEXT, Japan, and JSPS KAKENHI Grant Number 15J12515 and 25241005.
\end{abstract}

Open Access This article is distributed under the terms of the Creative Commons Attribution 4.0 International License (http:// creativecommons.org/licenses/by/4.0/), which permits unrestricted use, distribution, and reproduction in any medium, provided you give appropriate credit to the original author(s) and the source, provide a link to the Creative Commons license, and indicate if changes were made.

\section{References}

Abe-Ouchi A, Segawa T, Saito F (2007) Climatic Conditions for modelling the Northern Hemisphere ice sheets throughout the ice age cycle. Clim Past 3: 423-438. doi:10.5194/ cp-3-423-2007.

Abe-Ouchi A, Saito F, Kawamura K, Raymo ME, Okuno J, Takahashi K, Blatter H (2013) Insolation-driven 100,000-year glacial cycles and hysteresis of ice-sheet volume. Nature 500:190-193. doi:10.1038/nature12374

Abe-Ouchi A et al (2015) Ice-sheet configuration in the CMIP5/ PMIP3 last glacial maximum experiments. Geosci Model Dev 8, 3621-3637. doi:10.5194/gmd-8-3621-2015

Beghin P, Charbit S, Kageyama M, Combourieu-Nebout N, Hatté C, Dumas C, Peterschmitt JY (2015) What drives LGM precipitation over the western Mediterranean? A study focused on the Iberian Peninsula and northern Morocco. Clim Dyn. doi:10.1007/s00382-015-2720-0

Bitz CM, Holland MM, Hunke EC, Moritz RE (2005) Maintenance of the sea-ice edge. J Clim 18:2903-2921. doi:10.1175/jcli3428.1

Böhm E et al (2015) Strong and deep Atlantic meridional overturning circulation during the last glacial cycle. Nature 517:73-76. doi:10.1038/nature14059

Born A, Nisancioglu KH, Braconnot P (2010) Sea ice induced changes in ocean circulation during the Eemian. Clim Dyn 35:1361-1371. doi:10.1007/s00382-009-0709-2

Braconnot P et al (2007) Results of PMIP2 coupled simulations of the Mid-Holocene and Last Glacial Maximum-part 1: experiments and large-scale features. Clim Past 3:261-277. doi:10.5194/cp-3-261-2007

Braconnot P et al (2012) Evaluation of climate models using palaeoclimatic data. Nat Clim Change 2:417-424. doi:10.1038/ nclimate 1456

Brady EC, Otto-Bliesner BL, Kay JK, Rosenbloom N (2013) Sensitivity to glacial forcing in the CCSM4. J Clim 26:1901-1925. doi:10.1175/jcli-d-11-00416.1
Broccoli AJ, Manabe S (1987) The influence of continental ice, atmospheric $\mathrm{CO}_{2}$, and land albedo on the climate of the last glacial maximum. Clim Dyn 1:87-99. doi:10.1007/bf01054478

Brown N, Galbraith ED (2016) Hosed vs. unhorsed: interruptions of the Atlantic Meridional overturning circulation in a global coupled model, with and without freshwater forcing. Clim Past 12:1663-1679. doi:10.5194/cp-12-1663-2016

Chan W-L, Abe-Ouchi A, Ohgaito R (2011) Simulating the mid-Pliocene climate with the MIROC general circulation model: experimental design and initial results. Geosci Model Dev 4:10351049. doi:10.5194/gmd-4-1035-2011

Chavaillaz Y, Codron F, Kageyama M (2013) Southern westerlies in LGM and future (RCP4.5) climates. Clim Past 9:517-524. doi:10.5194/cp-9-517-2013

Chiang JCH, Bitz CM (2005) Influence of high latitude ice cover on the marine intertropical convergence zone. Clim Dyn 25:477496. doi:10.1007/s00382-005-0040-5

Chiang JCH, Biasutti M, Battisti DS (2003) Sensitivity of the Atlantic intertropical convergence zone to last glacial maximum boundary conditions. Paleoceanography 18:1094. doi:10.1029/200 3PA000916

Cook KH, Held IM (1988) Stationary waves of the ice age climate. J Clim 1:807-819. doi:10.1175/1520-0442(1988)001<0807:swot ia> 2.0.co;2

Cook KH, Held IM (1992) The stationary response to large-scale orography in a general circulation model and a linear model. J Atmos Sci 49:525-539. doi:10.1175/1520-0469(1992)049<0525:TSR TLS $>2.0 . \mathrm{CO} ; 2$

Dallenbach A, Blunier T, Fluckiger J, Stauffer B, Chappellaz J, Raynaud D (2000) Changes in the atmospheric $\mathrm{CH}_{4}$ gradient between Greenland and Antarctica during the last glacial and the transition to the Holocene. Geophys Res Lett 27:10051008. doi: $10.1029 / 1999 \mathrm{gl} 1010873$

Dee DP et al (2011) The ERA-Interim reanalysis: configuration and performance of the data assimilation system. Q J R Meteorolo Soc 137:553-597. doi:10.1002/qj.828

Eisenman I, Bitz CM, Tziperman E (2009) Rain driven by receding ice sheets as a cause of past climate change. Paleoceanography 24:PA4209. doi:10.1029/2009PA001778

Fluckiger J, Dallenbach A, Blunier T, Stauffer B, Stocker TF, Raynaud D, Barnola JM (1999) Variations in atmospheric $\mathrm{N}_{2} \mathrm{O}$ concentration during abrupt climatic changes. Science 285:227-230. doi:10.1126/science.285.5425.227

Gherardi J-M, Labeyrie L, Nave S, Francois R, McManus JF, Cortijo E (2009) Glcaial-interglacial circulation changes inferred from ${ }^{231} \mathrm{~Pa} /{ }^{230} \mathrm{Th}$ sedimentary record in the North Atlantic region. Paleoceanography 24:PA2204. doi:10.1029/2008PA001696

Gong X, Zhang XD, Lohmann G, Wei W, Zhang X, Pfeiffer M (2015) Higher Laurentide and Greenland ice sheets strengthen the North Atlantic ocean circulation. Clim Dyn 45:139-150. doi:10.1007/s00382-015-2502-8

Hasumi H (2002) Sensitivity of the global thermohaline circulation to interbasin freshwater transport by the atmosphere and the Bering Strait throughflow. J Clim 15:2516-2526. doi:10.1175/1520-0442(2002)015<2516:SOTGTC > 2.0.CO;2

Hasumi H (2006) CCSR Ocean Component Model (COCO) version 4.0, Report 25. Center For Climate System Research, University of Tokyo, Tokyo, p 103. http://ccsr.aori.u-tokyo.ac.jp/ hasumi/ COCO/index.html. Accessed 20 Apr 2013

Hasumi H, Emori S (2004) K-1 coupled model (MIROC) description. K-1 Technical Report 1, 34 pp., Center For Climate System Research, University of Tokyo, Tokyo

Held IM (1983) Stationary and quasi-stationary eddies in the extratropical troposphere: theory. In: Hoskins BJ, Pearce RP (eds) Large-scale dynamical processes in the atmosphere. Academic Press, Cambridge, pp 127-167 
Hofer D, Raible CC, Dehnert A, Kuhlemann J (2012) The impact of different glacial boundary conditions on atmospheric dynamics and precipitation in the North Atlantic region. Clim Past 8:935949. doi:10.5194/cp-8-935-2012

Hoskins BJ, Karoly DJ (1981) The steady linear response of a spherical atmosphere to thermal and orographic forcing. J Atmos Sci 38:1179-1196. doi:10.1175/1520-0469(1981)038<1179:tslroa $>2.0 . \mathrm{co} ; 2$

Hu AX, Meehl GA, Han WQ, Otto-Bliestner B, Abe-Ouchi A, Rosenbloom N (2015) Effects of the Bering Strait closure on AMOC and global climate under different background climates. Prog Oceanogr 132:174-196. doi:10.1016/j.pocean.2014.02.004

Hughes ALC, Gyllencreutz R, Lohne ØS, Mangerud, J, Svendsen JI (2016) The last Eurasian Ice Sheets-a chronological database and time-slice reconstruction, DATED-1. Boreas 45:1-45. doi:10.1111/bor.12142

Justino F, Timmermann A, Merkel U, Peltier WR (2006) An initial intercomparison of atmospheric and oceanic climatology for the ICE-5G and ICE-4G models of LGM paleotopography. J Clim 19:3-14. doi:10.1175/jcli3603.1

Kageyama M, Valdes PJ (2000) Impact of the North American icesheet orography on the last glacial maximum eddies and snowfall. Geophys Res Lett 27:1515-1518. doi:10.1029/199 $9 \mathrm{~g} 1011274$

Kageyama M, Valdes PJ, Ramstein G, Hewitt C, Wyputta U (1999) Northern hemisphere storm tracks in present day and last glacial maximum climate simulations: a comparison of the European PMIP models. J Clim 12:742-760. doi:10.1175/1520-0442(1999)012<0742:NHSTIP > 2.0.CO;2

Kageyama M et al (2006) Last Glacial Maximum temperatures over the North Atlantic, Europe and Western Siberia: a comparison between PMIP models, MARGO sea-surface temperatures and pollen-based reconstructions. Quat Sci Rev 25(17-18):20822102. doi:10.1016/j.quascirev.2006.02.010

Kageyama M, Mignot J, Swingedouw D, Marzin C, Alkama R, Marti O (2009) Glacial climate sensitivity to different states of the Atlantic Meridional Overturning Circulation: results from the IPSL model. Clim Past 5:551-570. doi:10.5194/cp-5-551-2009

Kawamura K et al (2017) State dependence of climatic instability over the past 720,000 years from Antarctic ice cores and climate modeling. Sci Adv 3:e1600446

Kobayashi H, Abe-Ouchi A, Oka A (2015) Role of Southern Ocean stratification in glacial atmospheric $\mathrm{CO}_{2}$ reduction evaluated by a three-dimensional ocean general circulation model. Paleoceanography 30:1202-1216. doi:10.1002/2015PA002786

Kuhlbrodt T, Griesel A, Montoya M, Levermann A, Hofmann M, Rahmstorf S (2007) On the driving processes of the Atlantic meridional overturning circulation. Rev Geophys. doi:10.1029 /2004rg000166.

Laîné A et al (2009) Northern hemisphere storm tracks during the last glacial maximum in the PMIP2 ocean-atmosphere coupled models: energetic study, seasonal cycle, precipitation. Clim Dyn 32:593-614. doi:10.1007/s00382-008-0391-9

Langen PL, Vinther BM (2009) Response in atmospheric circulation and sources of Greenland precipitation to glacial boundary conditions. Clim Dyn 32:1035-1054. doi:10.1007/ s00382-008-0438-y

Li C, Battisti DS (2008) Reduced Atlantic storminess during last glacial maximum: evidence from a coupled climate model. J Clim 21:3561-3579. doi:10.1175/2007jcli2166.1

Liakka J (2012) Interactions between topographically and thermally forced stationary waves: implications for ice-sheet evolution. Tellus Series a Dyn Meteorol Oceanogr 64 A:11088. doi:10.3402/tellusa.v64i0.11088

Liakka J, Nilsson J, Löfverström M (2012) Interactions between stationary waves and ice sheets: linear versus nonlinear atmospheric response. Clim Dyn 38:1249-1262. doi:10.1007/ s00382-011-1004-6

Lippold J, Luo Y, Francois R, Allen SE, Gherardi J, Pichat S, Hickey B, Schulz H (2012) Strength and geometry of the glacial Atlantic meridional overturning circulation. Nat Geosci 5:813-816. doi:10.1038/ngeo1608

Lisiecki LE, Raymo ME (2005) A Pliocene-Pleistocene stack of 57 globally distributed benthic delta O-18 records. Paleoceanography 20:PA1003. doi:10.1029/2004PA001071

Liu ZY, Shin SI, Webb RS, Lewis W, Otto-Bliesner BL (2005) Atmospheric $\mathrm{CO}_{2}$ forcing on glacial thermohaline circulation and climate. Geophys Res Lett 32:L02706. doi:10.1029/200 $4 \mathrm{gl} 021929$

Löfverström M, Caballero R, Nilsson J, Kleman J (2014) Evolution of the large-scale atmospheric circulation in response to changing ice sheets over the last glacial cycle. Clim Past 10:1453-1471. doi:10.5194/cp-10-1453-2014

Löfverström M, Liakka J, Kleman J (2015) The North American Cordillera-An impediment to growing the continent-wide laurentide ice sheet. J Clim 28:9433-9450. doi:10.1175/JCLI-D-15-0044.1

Lü JM, Kim SJ, Abe-Ouchi A, Yu Y, Ohgaito R (2010) Arctic Oscillation during the mid-Holocene and last glacial maximum from PMIP2 coupled model simulations. J Clim 23:3792-3813. doi:1 $0.1175 / 2010 J C L I 3331.1$

Lynch-Stieglitz J et al (2007) Atlantic meridional overturning circulation during the last glacial maximum. Science 316:66-69. doi: $10.1126 /$ science. 1137127

Manabe S, Broccoli AJ (1985) The influence of continental ice sheets on the climate of an ice age. J Geophys Res Atmos 90:21672190. doi:10.1029/JD090iD01p02167

Marshall J, Schott F (1999) Open-ocean convection: observations, theory, and models. Rev Geophys 37(1):1-64. doi:10.1029/98RG02739

Masson-Delmotte V et al (2006) Past and future polar amplification of climate change: climate model intercomparisons and ice-core constraints. Clim Dyn 26:513-529. doi:10.1007/ s00382-005-0081-9

McManus JF, Francois R, Gherardi JM, Keigwin LD, Brown-Leger $S$ (2004) Collapse and rapid resumption of Atlantic meridional circulation linked to deglacial climate changes. Nature 428:834-837. doi:10.1038/nature02494

Merz N, Raible CC, Woollings T (2015) North Atlantic Eddy-Driven Jet in Interglacial and Glacial Winter Climates. J Clim 28:39773997. doi:10.1175/jcli-d-14-00525.1

Monnin E et al (2001) Atmospheric $\mathrm{CO}_{2}$ concentrations over the last glacial termination. Science 291:112-114. doi:10.1126/ science.291.5501.112

Montoya M, Levermann A (2008) Surface wind-stress threshold for glacial Atlantic overturning. Geophys Res Lett 35:L03608. doi: 10.1029/2007g1032560

Montoya M, Born A, Levermann A (2011) Reversed North Atlantic gyre dynamics in present and glacial climates. Clim Dyn 36:1107-1118. doi:10.1007/s00382-009-0729-y

Muglia J, Schmittner A (2015) Glacial Atlantic overturning increased by wind stress in climate models. Geophys Res Lett 42:98629869. doi:10.1002/2015GL064583

Murakami S, Ohgaito R, Abe-Ouchi A, Crucifix M, Otto-Bliesner BL (2008) Global scale energy and freshwater balance in glacial climate: a comparison of three PMIP2 LGM simulations. J Clim 21:5008-5033. doi:10.1175/2008JCL12104.1

Nozawa T, Nagashima T, Shiogama H, Crooks SA (2005) Detecting natural influence on surface air temperature change in the early twentieth century. Geophys Res Lett 32:L20719. doi:10.1029/2 005GL023540.

Numaguti A, Takahashi M, Nakajima T, Sumi A (1997) Description of CCSR/NIES Atmospheric General Circulation Model. 
CGER's Supercomputer Monograph Report, Center for Global Environmental Research, National Institute for Environmental Studies, No. 3, 1-48.

O'ishi R, Abe-Ouchi A (2009) Influence of dynamic vegetation change on climate change arising from increasing $\mathrm{CO}_{2}$. Clim Dyn 33:645-663. doi:10.1007/s00382-009-0611-y

Ogura T, Abe-Ouchi A (2001) Influence of the Antarctic ice sheet on southern high latitude climate during the Cenozoic: Albedo vs topography effect. Geophys Res Lett 28:587-590. doi:10.1029 /2000gl011366

Ohgaito R, Abe-Ouchi A (2009) The effect of sea surface temperature bias in the PMIP2 AOGCMs on mid-Holocene Asian monsoon enhancement. Clim Dyn 33:975-983. doi:10.1007/ s00382-009-0533-8

Oka A, Hasumi H, Suginohara N (2001) Stabilization of thermohaline circulation by wind-driven and vertical diffusive salt transport. Clim Dyn 18:71-83. doi:10.1007/s003820100159

Oka A, Kato S, Hasumi H (2008) Evaluating effect of ballast mineral on deep-ocean nutrient concentration by using an ocean general circulation model. Global Biogeochem Cycles 22:GB3004. doi: 10.1029/2007GB003067

Oka A, Hasumi H, Abe-Ouchi A (2012) The thermal threshold of the Atlantic meridional overturning circulation and its control by wind stress forcing during glacial climate. Geophys Res Lett 39:L09709. doi:10.1029/2007g1029475

Otto-Bliesner BL et al (2007) Last Glacial Maximum ocean thermohaline circulation: PMIP2 model intercomparisons and data constraints. Geophys Res Lett 34:L12706. doi:10.1029/200 $7 \mathrm{gl} 1029475$

Otto-Bliesner BL et al (2009) Comparison of PMIP2 Model Simulations and the MARGO proxy reconstruction for tropical sea surface temperatures at last glacial maximum. Clim Dyn 32:799815. doi:10.1007/s00382-008-0509-0

Pausata FSR, Li C, Wettstein JJ, Kageyama M, Nisancioglu KH (2011) The key role of topography in altering North Atlantic atmospheric circulation during the last glacial period. Clim Past 7:1089-1101. doi:10.5194/cp-7-1089-2011

Peltier WR (1994) Ice-age paleotopography. Science 265:195-201. doi:10.1126/science.265.5169.195

Peltier WR (2004) Global glacial isostasy and the surface of the ice-age earth: the ice-5G (VM2) model and grace. Annu Rev Earth Planet Sci 32:111-149. doi:10.1146/annurev. earth.32.082503.144359

Ringler TD, Cook KH (1997) Factors controlling nonlinearity in mechanically forced stationary waves over orography. J Atmos Sci 54:2612-2629. doi:10.1175/1520-0469(1997)054<2612:FCNIMF>2.0CO;2

Ringler TD, Cook KH (1999) Understanding the seasonality of orographically forced stationary waves: interaction between mechanical and thermal forcing. J Atmos Sci 56:1154-1174. doi:10.1175/1520-0469(1999)056<1154:UTSOOF>2.0.CO;2

Rivière G, Laîné A, Lapeyre G, Salas-Mélia D, Kageyama M (2010) Links between Rossby wave breaking and the North Atlantic Oscillation-Arctic Oscillation in present-day and last glacial maximum climate simulations. J Clim 23:2987-3008. doi:10.1 175/2010JCLI3372.1

Roche DM, Crosta X, Renssen H (2012) Evaluating Southern Ocean sea-ice for the last glacial maximum and pre-industrial climate2: PMIP-2 models and data evidence. Quat Sci Rev 56:99106. $10.1016 /$ j.quascirev.2012.09.020

Roe GH, Lindzen RS (2001a) A one-dimensional model for the interaction between continental-scale ice sheets and atmospheric stationary waves. Clim Dyn 17:479-487. doi:10.1007/ S003820000123

Roe GH, Lindzen RS (2001b) The mutual interaction between continental-scale ice sheets and atmospheric stationary waves. J Clim
14:1450-1465. doi:10.1175/1520-0442(2001)014<1450:tmibcs $>2.0 . \operatorname{co} ; 2$

Rojas M et al (2009) The Southern Westerlies during the last glacial maximum in PMIP2 simulations. Clim Dyn 32:525-548. doi:10.1007/s00382-008-0421-7

Saenko OA (2009a) Sensitivity of the subpolar Atlantic climate to local winds. Geophys Res Lett 36:L03604. doi:10.1029/200 $8 \mathrm{gl} 1036308$

Saenko OA (2009b) On the climatic impact of wind stress. J Phys Oceanogr 39:89-106. doi:10.1175/2008jpo3981.1

Saenko OA, Schmittner A, Weaver AJ (2002) On the role of winddriven sea ice motion on ocean ventilation. J Clim 32:33763395. doi:10.1175/1520-0485(2002)032\%3C3376:OTROWD\% 3E2.0.CO;2

Schmittner A (2003) Southern Ocean sea ice and radiocarbon ages of glacial bottom waters. Earth Planet Sci Lett 213:53-62. doi:10.1016/S0012-821X(03)00291-7

Shin SI, Liu ZG, Otto-Bliesner BL, Kutzbach JE, Vavrus SJ (2003) Southern Ocean sea-ice control of the glacial North Atlantic thermohaline circulation. Geophys Res Lett 30(2):1096. doi:10. 1029/2002gl015513

Singarayer JS, Valdes PJ (2010) High-latitude climate sensitivity to ice-sheet forcing over the last 120 kyr. Quat Sci Rev 29:43-55. doi:10.1016/j.quascirev.2009.10.011

Smith RS, Gregory J (2012) The last glacial cycle: transient simulations with an AOGCM. Clim Dyn 38:1545-1559. doi:10.1007/ s00382-011-1283-y

Steele M, Zhang JL, Rothrock D, Stern H (1997) The force balance of sea ice in a numerical model of the Arctic Ocean. J Geophys Res Oceans 102:21061-21079. doi:10.1029/97jc01454

Steele M, Morley R, Ermold W (2001) PHC: A global ocean hydrography with a high-quality Arctic Ocean. J Clim 14:2079-2087. doi:10.1175/1520-0442(2001)014<2079:pagohw>2.0.co;2

Stokes CR, Tarasov L, Dyke AS (2012) Dynamics of the North American Ice Sheet complex during its inception and build-up to the last glacial maximum. QSR. doi:10.1016/j. quascirev.2012.07.009

Stouffer RJ, Manabe S (2003) Equilibrium response of thermohaline circulation to large changes in atmospheric $\mathrm{CO}_{2}$ concentration. Clim Dyn 20:759-773. doi:10.1007/s00382-002-0302-4

Talley LD, Reid JL, Robbins PE (2003) Data-based meridional overturning streamfunctions for the global ocean. J Clim 16:32133226. doi:10.1175/1520-0442(2003)016\%3C3213:DMOSFT\%3 $\mathrm{E} 2.0 . \mathrm{CO} ; 2$

Timmermann A, Goosse H (2004) Is the wind stress forcing essential for the meridional overturning circulation? Geophys Res Lett 31:L04303. doi:10.1029/2003g1018777

Trenberth KE, Chen SC (1988) Planetary waves kinematically forced by Himalayan orography. J Atmos Sci 45:2934-2948. doi:10.1175/1520-0469(1988)045<2934:PWKFBH>2.0.CO;2

Ullman DJ, LeGrande AN, Carlson AE, Anslow FS, Licciardi JM (2014) Assessing the impact of Laurentide Ice Sheet topography on glacial climate. Clim Past 10:487-507. doi:10.5194/ cp-10-487-2014.

Vettoretti G, Peltier WR (2013) Last Glacial maximum ice sheet impacts on North Atlantic climate variability: the importance of the sea ice lid. Geophys Res Lett 40:6378-6383. doi:10.1002/2 $013 \mathrm{~g} 1058486$

Watanabe $M$ et al (2010) Improved simulation by MIROC5: mean states, variability, and climate sensitivity. J Clim 23(23):63126335. doi:10.1175/2010JCLI3679.1

Weber SL et al (2007) The modern and glacial overturning circulation in the Atlantic Ocean in PMIP coupled model simulations. Clim Past 3:51-64. doi:10.5194/cp-3-51-2007

Yanase W, Abe-Ouchi A (2007) The LGM surface climate and atmospheric circulation over East Asia and the North Pacific in the 
PMIP2 coupled model simulations. Clim Past 3:439-451. doi:10.5194/cp-3-439-2007

Yanase W, Abe-Ouchi A (2010) A Numerical Study on the Atmospheric Circulation over the Midlatitude North Pacific during the last glacial maximum. J Clim 23:135-151. doi:10.1175/2009j cli3148.1

Zhang X, Lohmann G, Knorr G, Purcell C (2014) Abrupt glacial climate shifts controlled by ice sheet changes. Nature 512:290294. doi:10.1038/nature13592
Zhong Y et al (2011) Centennial-scale climate change from decadallypaced explosive volcanism: a coupled sea ice-ocean mechanism. Clim Dyn 37:2373-2387. doi:10.1007/s00382-010-0967-z

Zhu J, Liu ZY, Zhang X, Eisenman I, Liu W (2014) Linear weakening of the AMOC in response to receding glacial ice sheets in CCSM3. Geophys Res Lett 41:6252-6258. doi:10.1002/201 $4 \mathrm{gl} 1060891$ 